\title{
Multilayer Cloud Detection with the MODIS Near-Infrared Water Vapor Absorption Band
}

\author{
GALINA WIND \\ NASA Goddard Space Flight Center, Greenbelt, Maryland \\ SSAI, Inc \\ STEVEN PLATNICK \\ NASA Goddard Space Flight Center, Greenbelt, Maryland \\ MICHAEL D. KING \\ Laboratory for Atmospheric and Space Physics, University of Colorado - Boulder, Boul- \\ der, Colorado \\ PAUL A. HuBANKS \\ NASA Goddard Space Flight Center, Greenbelt, Maryland \\ Wyle, Inc \\ MichaEL J. PAVOLONIS \\ Center for Satellite Applications and Research (STAR), NOAA/NESDIS, Madison, Wis- \\ consin \\ ANDREW K. HEIDINGER \\ Center for Satellite Applications and Research (STAR), NOAA/NESDIS, Madison, Wis- \\ consin \\ PING YANG \\ Department of Atmospheric Sciences, Texas A\&M University, College Station, Texas \\ BRYAN A. BAUM \\ Space Science and Engineering Center, University of Wisconsin-Madison, Madison, \\ Wisconsin
}

Journal of Applied Meteorology and Climatology

(Manuscript submitted 21 July 2009)

Corresponding author address: Galina Wind, Code 613.2, NASA Goddard Space Flight Center, Greenbelt, MD 20771. E-mail: gala.wind@nasa.gov. 



\begin{abstract}
Data Collection 5 processing for the Moderate Resolution Imaging Spectroradiometer (MODIS) onboard the NASA Earth Observing System EOS Terra and Aqua spacecraft includes an algorithm for detecting multilayered clouds in daytime. The main objective of this algorithm is to detect multilayered cloud scenes, specifically optically thin ice cloud overlying a lower-level water cloud, that presents difficulties for retrieving cloud effective radius using single layer plane-parallel cloud models. The algorithm uses the MODIS $0.94 \mu \mathrm{m}$ water vapor band along with $\mathrm{CO}_{2}$ bands to obtain two above-cloud precipitable water retrievals, the difference of which, in conjunction with additional tests, provides a map of where multilayered clouds might potentially exist. The presence of a multilayered cloud results in a large difference in retrievals of above-cloud properties between the $\mathrm{CO}_{2}$ and the $0.94 \mu \mathrm{m}$ methods. In this paper the MODIS multilayered cloud algorithm is described, results of using the algorithm over example scenes are shown, and global statistics for multilayered clouds as observed by MODIS are discussed. A theoretical study of the algorithm behavior for simulated multilayered clouds is also given. Results are compared to two other comparable passive imager methods. A set of standard cloudy atmospheric profiles developed during the course of this investigation is also presented. The results lead to the conclusion that the MODIS multilayer cloud detection algorithm has some skill in identifying multilayered clouds with different thermodynamic phases.
\end{abstract}





\section{Introduction}

Plane-parallel single-layered cloud radiative transfer (RT) models are used by global passive imager algorithms like MODIS (MODerate resolution Imaging Spectroradiometer) (Barnes et al. 1998) for cloud thermodynamic phase, cloud-top pressure/temperature, and optical and microphysical properties retrievals (King et al. 2003; Platnick et al. 2003). The use of such a RT model works reasonably well as confirmed by many field campaigns and theoretical calculations (King et al. 2004; Mace et al. 2005; Chiriaco et al. 2007; Bedka et al. 2007; Otkin et al. 2008). The model can work for some retrievals if there are multilayered clouds in a vertical column (e.g., an ice cloud overlapping a liquid water cloud) and the uppermost layer is optically thick. In particular, use of the RT model can result in biases with cloud effective radius retrievals when liquid water clouds are overlaid by relatively thin cirrus clouds (Davis et al. 2009). The retrieved effective radius of what is thought to be single layer ice clouds decreases significantly in areas overlying the water clouds. When the cirrus is too optically thin to dominate the upwelling radiance and the cloud is identified as being liquid water phase, the retrieval tends towards abnormally large water droplets. There is not a large detrimental effect on cloud optical thickness to the extent that the combined optical thickness of all layers is retrieved with little dependence on the assumed phase.

It is important to flag areas where there are problematic effective radius retrievals due to multilayer clouds of differing thermodynamic phases since those retrievals can adversely affect cloud statistics and should be excluded from further analysis.

There have been other algorithms designed to identify multilayer clouds with passive imagers. The algorithm developed by Pavolonis and Heidinger (2004) is a pixel-level algorithm that uses ratios and differences of reflectances and brightness temperatures in various bands. This approach can be applied to historical and current multispectral imager data such as the AVHRR (Advanced Very High Resolution Radiometer) on the NOAA spacecraft and MODIS. Such an approach may also be continued with future 
measurements from the VIIRS (Visible/Infrared Imager Radiometer Suite) that will be flown on the NPOESS (National Polar-orbiting Operational Environmental Satellite System) platforms. This multispectral approach uses ratios and differences of reflectances and brightness temperatures. We will show a comparison of this AVHRR-VIIRS algorithm with the MODIS algorithm in section 5.

The algorithm developed by Baum and Nasiri (Baum et al. 2000; Nasiri and Baum 2004) is a statistically based algorithm that is executed in shifting steps over a box area of user-defined size, typically $200 \times 200$ pixels, with a restriction that some clear sky is available in the area; the algorithm retrieves a probability that the cloud is multilayered. This algorithm was developed for the MODIS instrument, but has not been used extensively outside of case studies. The need to use a large area to work on and a requirement for presence of clear sky pixels within each work area reduces the effective algorithm resolution and usefulness as many multilayered cloud retrievals occur within synoptic systems that span a wide area with extensive cloud cover. We will show a comparison of our algorithm with the Nasiri-Baum algorithm in section 5.

Another approach for multilayer cloud detection has been presented by Chang and $\mathrm{Li}$ (Chang and Li 2005a,b). The method of Chang and Li uses an estimation of cirrus cloud emissivity based on the difference of cloud top temperature retrieved by using the $\mathrm{CO}_{2}$

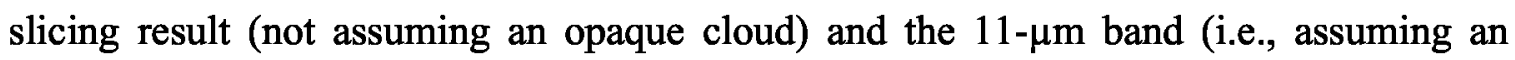
opaque cloud). The algorithm relies on being able to identify single-layer liquid water clouds and clear sky pixels in an area of $250 \times 250 \mathrm{~km}$ centered on the point of interest. The cloud effective emissivity is then computed, from which the infrared (IR) cloud optical thickness is derived. If that cloud optical thickness is significantly different from the cloud optical thickness retrieved using a visible or shortwave infrared (SWIR) band, the cirrus cloud likely has a liquid water cloud underneath it.

The MODIS operational multilayer cloud detection algorithm relies on a difference 
in above-cloud precipitable water retrievals obtained from using the $0.94 \mu \mathrm{m}$ band versus precipitable water computed from the $\mathrm{CO}_{2}$ slicing-derived cloud top altitude. The 0.94 $\mu \mathrm{m}$ band is relatively insensitive to optically thin cirrus and so the column moisture is integrated from the top of the atmosphere (TOA) to the lower level cloud, if such is present. The $\mathrm{CO}_{2}$ slicing retrieval of cloud top height, and subsequent calculation of the above-cloud precipitable water from a forecast model profile, occurs from the TOA to the level of the higher cloud. From that difference, and several other tests such as the difference between retrieved IR and SWIR cloud thermodynamic phases and reflectance ratios to screen for single layer clouds over bright surfaces, a determination is made as to whether or not the cloud is multilayered in a way that affects the applicability of the plane-parallel single layer cloud models used in retrievals of cloud effective radius.

Initial CloudSat evaluations of the MODIS multilayer cloud detection algorithm have been done by Joiner et al.(2010) as part of a study which developed a global multilayer cloud detection algorithm via cloud top pressure derived from the Aura Ozone Monitoring Instrument (OMI) .

In the following discussion we present the MODIS operational multilayer cloud detection algorithm, describe how the multilayer cloud information is stored in the MOD06/MYD06 Level-2 HDF (Hierarchical Data Format) files, present results of executing the algorithm on data produced by forward simulations of multilayered clouds, and compare the algorithm to other methods.

A useful cloud simulation data set was developed using a set of moist atmospheres from the ECMWF (European Centre for Medium-Range Weather Forecasts) 40-year reanalysis data set. Selected profiles were chosen at grid points that contained sufficient amounts of cloud to create a more realistic setting into which well-separated cloud layers were inserted. The profiles created in this fashion are available at http://modisatmos.gsfc.nasa.gov/MOD06_L2/validation.html. 
To summarize briefly the discussion that will follow, section 2 describes the algorithm and the data format in which the results are stored. Section 3 presents the details of the RT simulations and describes in detail the method used to create the simulation data set. Section 4 provides results from applying the MODIS operational multilayer cloud detection algorithm over the simulated scenes as well as selected MODIS data granules, and also provides an example of global statistical aggregation of multilayer cloud data. Section 5 discusses a direct comparison of our results with other passive remote sensor methods for detecting multilayer clouds. Conclusions, ongoing work and future directions are discussed in section 6.

\section{Algorithm description}

The operational MODIS multilayer cloud retrieval uses a number of bands in addition to individual retrievals of physical quantities such as above-cloud precipitable water and cloud optical thickness, to arrive at a decision. The main component of the retrieval is a test for the difference of above-cloud precipitable water retrievals obtained by two different methods.

The first method is based on the cloud top pressure retrieval obtained from $\mathrm{CO}_{2}$ slicing using ratios of MODIS bands 33, 34, 35 and 36 that are centered between 13.3 and 14.2 $\mu \mathrm{m}$ (Menzel et al. 2008). The retrieved cloud top pressure is then used to obtain above-cloud water vapor amount $\left(\mathrm{PW}_{\mathrm{CO} 2}\right)$ by adding up the layer averaged water vapor amounts from the NCEP (National Centers for Environmental Prediction) global 6-hour atmospheric profile product, produced at $1^{\circ}$ resolution. Due to the nature of $\mathrm{CO}_{2}$ absorption, the algorithm is sensitive to high clouds of optical thickness $\left(\tau_{c}\right)$ greater than 0.5 (Menzel et al. 2008) when multilayer clouds are present and will return a low value of above-cloud precipitable water.

The second method uses water vapor absorption in the MODIS 0.94- $\mu \mathrm{m}$ band. Above-cloud precipitable water is retrieved using an iterative approach. That is possible 
because cloud reflectance is flat in the spectral range between 0.86 and $0.94 \mu \mathrm{m}$ and the difference in measured cloud reflectance is due to the water vapor amount between the cloud and the sensor. If the visible optical thickness of thin cirrus layer is less than 6 , the $0.94 \mu \mathrm{m}$ band is sensitive to the low clouds when multilayer clouds are present and will return a higher value of above-cloud precipitable water than the $\mathrm{CO}_{2}$ slicing method would. The discrepancy in retrieved amounts of above-cloud precipitable water can be attributed to the presence of multilayered clouds.

The MODIS operational multilayer algorithm first assumes that a single layered cloud exists, with a cloud top temperature based on the $11-\mu \mathrm{m}$ brightness temperature. Cloud-top pressure is then inferred by mapping the temperature into the NCEP pressure profile. The mapping is done from the top downward so as to avoid the high likelihood of temperature inversions nearer the surface.

This cloud top pressure together with the view geometry is used to index a MODIS atmospheric transmittance table for $0.86 \mu \mathrm{m}$ and $0.94 \mu \mathrm{m}$, which is generated by using the ECMWF ERA-40 atmospheric profile database as input to MODTRAN (MODerate resolution atmospheric TRANsmission) version 4.2r1 (Berk et al. 1998). This lookup results in a vector of two-way atmospheric transmittance as a function of above-cloud precipitable water for each band. These transmittance vectors are then applied to the measured reflectances. The dominant contributor to absorption in the $0.94 \mu \mathrm{m}$ band is water vapor. If there were no water vapor between observer and cloud, measured reflectances can be assumed to be identical. Using that assumption we look for a point where the two vectors intersect. The closest table index value of precipitable water at the intersection point is our retrieval of above-cloud precipitable water $\left(\mathrm{PW}_{0.94}\right)$. We choose to neglect a very small amount of ozone absorption in the $0.86 \mu \mathrm{m}$ band $(<0.001$ additional absorption amount) as it has no discernible impact on location of the intersection point due to lookup table resolution. 
We then use the retrieved water vapor amount to perform a crude atmospheric emission correction on the $11 \mu \mathrm{m}$ radiance. Measured $11 \mu \mathrm{m}$ radiance consists of three components: emission from ground, emission from cloud and emission from atmosphere above cloud. We assume that cloud emissivity is unity, therefore we do not deal with emission from ground. This is the exact assumption made by MODIS $\mathrm{CO}_{2}$ slicing-based cloud top properties retrieval method. Now we must subtract the atmospheric emission from measurement and also correct the result for water vapor absorption in the $11 \mu \mathrm{m}$ channel. So the final corrected radiance takes on the following form:

$$
I_{\text {corr }}=\frac{I_{\text {meas }}-B\left(T_{\text {mean_above_cloud }}\right) *(1-\text { trans })}{\text { trans }},
$$

where $I_{\text {meas }}$ is the measured radiance, $T_{\text {mean_above_cloud }}$ is the integrated layer mean temperature from given atmospheric profile and trans is the 1-way atmospheric transmittance at $11 \mu \mathrm{m}$.

The entire process is repeated using the corrected $11 \mu \mathrm{m}$ radiance as a source of cloud top temperature. We have found that one additional iteration is enough for the retrieval to converge to within $0.25 \mathrm{~K}$, which we consider to be a sufficient degree of accuracy for our purpose. This same type of retrieval, but without iteration, is also performed one additional time with the assumption that the cloud in question is located at $900 \mathrm{hPa}$ $\left(\mathrm{PW}_{0.94 @ 900)}\right)$. If a high, cold cloud $\left(\mathrm{T}_{\mathrm{c}}<265 \mathrm{~K}\right)$ with little water vapor above it is moved vertically in the atmosphere, its retrieved temperature and pressure stay nearly constant because atmospheric transmittance for amounts of water vapor less than $0.5 \mathrm{~cm}$ shows very little dependence on pressure. Moving such cloud from $200 \mathrm{mb}$ down to $900 \mathrm{mb}$ changes $11 \mu \mathrm{m}$ transmittance by only $0.8 \%, 0.94 \mu \mathrm{m}$ transmittance by $1.05 \%$ and $0.86 \mu \mathrm{m}$ by $0.01 \%$. However, this is not so for a warm, low cloud with a significant amount $(>1$ $\mathrm{cm}$ ) of water vapor above it, which is fairly typical for boundary layer clouds. For such cloud $11 \mu \mathrm{m}$ and $0.86 \mu \mathrm{m}$ transmittances change by about the same amount as for a high 
cloud, but the $0.94 \mu \mathrm{m}$ transmittance changes by $8 \%$ if such cloud with $1 \mathrm{~cm}$ of precipitable water above it is moved between 600 and $900 \mathrm{mb}$. The error in retrieved precipitable water amount for the lower level cloud will increase as the optical thickness of the overlaying ice cloud increases. The result is similar regardless of where the lower-level cloud lies between 800 and $1000 \mathrm{hPa}$. A low-level cloud pressure of $900 \mathrm{hPa}$ is chosen as the default value. We mitigate the effect of ground elevation due to the fact that the NCEP profiles extrapolate every profile down to $1000 \mathrm{mb}$ level, regardless of terrain. A precipitable water retrieval based on this assumption acts to mitigate the 'cooling' effect of an upper ice cloud and results in the inference of a more realistic high precipitable water amount above the lower level cloud. This process does not affect the results for singlelayered ice clouds or multilayered clouds where the upper ice cloud layer is optically thick, and permits the tracking of more multilayered clouds.

As both $0.94 \mu \mathrm{m}$ and $0.86 \mu \mathrm{m}$ channels are much more sensitive to the presence of lower-level clouds in multilayer situations, the retrieved precipitable water value is quite different from the same retrieval performed based on the inference of high clouds from $\mathrm{CO}_{2}$ slicing. That difference, weighted by the total column precipitable water (TPW), is a key determinant of whether or not there may be multilayered clouds present. A value of

$$
\frac{\left|P W_{0.94}-P W_{C O 2}\right|}{T P W}>8 \%
$$

is used as the threshold for marking the pixel as potentially containing multilayered clouds based on case studies and estimates regarding the occurrence of effective radius biases (see following example). Forward radiative transfer simulations, discussed in sections 3 and 4, confirm that this an appropriate choice.

Figure 1 illustrates the effect of this retrieval on a portion of a MODIS data granule. These data were collected from Terra MODIS on 25 October 2008 at 0015 UTC in the western Pacific Ocean just east of Japan. The panels show the process of obtaining a multilayer result using the precipitable water method. Figure 1a shows a false-color image of 
MODIS bands $6,2,26(1.64,0.86$, and $1.38 \mu \mathrm{m}$, respectively). Thin cirrus is advecting over a field of cumuliform clouds. In this false-color composite, liquid water clouds appear gold, ice clouds appear blue and white, and the ocean surface appears black. A number of areas where thin cirrus overlaps the liquid water clouds are visible in the image and take on a greenish hue. Figure $1 \mathrm{~b}$ is an image of above-cloud precipitable water from the MODIS cloud top properties algorithm that uses $\mathrm{CO}_{2}$ slicing $\left(\mathrm{PW}_{\mathrm{CO}_{2}}\right)$. The figure shows a strong preference for high cloud properties in the overlap region, and thus a low water vapor amount is derived above clouds. There is barely a trace of the low-level clouds in the image. Very low values of precipitable water are seen for the high clouds as expected. Figure $1 \mathrm{c}$ is an image of the standard $0.86-0.94 \mu \mathrm{m}$ retrieval of precipitable water $\left(\mathrm{PW}_{0.94}\right)$, which is more sensitive to low clouds and so gives higher precipitable water values that are more typical for those clouds. Figure $1 \mathrm{~d}$ is the difference image between the precipitable water from the $\mathrm{CO}_{2}$ slicing and the $0.94 \mu \mathrm{m}$ algorithm. Outlines of lowlevel clouds are becoming clearly visible in the difference image. Small differences in precipitable water correspond to either thicker cirrus, which is not sensitive to multilayer clouds, or breaks in the low-level cumulus clouds. But more cloud could be flagged as the cirrus becomes thicker to the west and is affecting the vertical placement of the cumulus. Figure 1e shows the precipitable water retrieval in which the low-level clouds are assumed to be at the $900 \mathrm{hPa}$ level. It is not that different from the main 0.86-0.94 $\mu \mathrm{m}$ result with the exception that it captures some of the cloud features covered by somewhat thicker cirrus to the west. Even though the clouds are thicker, they still contain some contribution from the underlying low-level cloud. Figure 1f shows the difference image resulting from the $900 \mathrm{hPa}$ retrieval versus that from the $\mathrm{CO}_{2}$ slicing.

The final two images are the retrieved cloud optical thickness and effective radius for the scene. The warm colors indicate liquid water clouds with cold colors for ice cloud retrievals. The optical thickness image indicates that the cirrus is quite thin and fairly uni- 
form over the overlap area. There is no significant impact of multilayered clouds on optical thickness as the overlying cirrus is thin and its contribution to the combined visible optical thickness is very small. In contrast, the impact on the cloud effective radius retrieval is much greater. The outlines of low-level clouds are clearly seen in the effective radius image as areas of small ice effective radii. The breaks of open water in the cumulus cloud fields return effective radius values of around $25 \mu \mathrm{m}$, so it is unlikely that the actual cloud microphysics is changing in the overlap area.

Figure 2 shows the net statistical effect of multilayer clouds on cloud optical thickness and cloud effective radius. While there is not a large effect on cloud optical thickness, there is a significant shift in effective radius distribution towards smaller radii when multilayered clouds are not removed from the scene. In this particular case $19.2 \%$ of ice cloud in the scene was multilayer and $\sim 54,000$ pixels were removed from the distribution.

The MODIS $\mathrm{CO}_{2}$ slicing algorithm is applied with the most confidence for clouds at pressures lower than about $700 \mathrm{hPa}$ (Menzel et al. 2008). In a typical MODIS scene, however, the $\mathrm{CO}_{2}$ slicing algorithm is rarely applied for clouds at pressures larger than $600 \mathrm{hPa}$. If the $\mathrm{CO}_{2}$ slicing algorithm is unable to converge on a solution, the $11-\mu \mathrm{m}$ band is used under the assumption that there is a low-level opaque cloud present. The choice was made to ignore $\mathrm{CO}_{2}$ slicing results at pressures larger than $550 \mathrm{hPa}$ to minimize the potential for false positive retrievals. In light of improvement in vertical resolution to 101 levels used in MODIS $\mathrm{CO}_{2}$ slicing algorithm beginning with Collection 6, this $550 \mathrm{hPa}$ restriction may be eased in the future, although uncertainties due to resolution of the NCEP profiles will remain.

Due to uncertainties in inferring cloud emissivity from passive sensors, it is possible to obtain a false positive multilayer retrieval for the case when an optically thin cirrus cloud is present with $\tau_{c}<4$. If the cloud is very optically thin, upwelling radiance from surface will cause that cloud to be placed at pressure much higher than truth. That means 
the $0.94 \mu \mathrm{m}$ cloud top properties method will retrieve much higher precipitable water amount than $\mathrm{CO}_{2}$ slicing would because of surface contamination and not because of multilayer situation. We assume that if the total column optical thickness is $<4$, the likelihood is that there is not a lower cloud underneath it. The liquid water cloud layer underneath would most likely push the total optical thickness above 4. If a liquid water cloud is so thin that threshold of 4 is not reached, then we would have difficulty with retrieving effective radius due to shape of forward library space (Platnick, et.al. 2003), any multilayer situation aside. False negatives do arise from use of this threshold, but with overall effective radius retrieval uncertainty being well above $20 \%$ for thin clouds, the weight of such retrievals should be greatly reduced in any statistical studies anyhow.

We also must consider cases of single-layer clouds over bright surfaces. It is possible for the algorithm to mistake a thin cirrus cloud over a bright surface for a cloud that is multilayer. The $0.65 \mu \mathrm{m}$ and the $1.24 \mu \mathrm{m}$ reflectances are used to check for vegetation and snow/ice, respectively. Cloud reflectance is reasonably flat in that spectral region, while surface albedo changes significantly. So for a true multilayer cloud situation, the reflectance ratio would be close to 1.0 , but not so for a single layer of thin cirrus over a bright surface. It is useful to use ratios of $0.86 \mu \mathrm{m}$ reflectance to $0.65 \mu \mathrm{m}$ and $1.24 \mu \mathrm{m}$ reflectance to check for bright surfaces, with thresholds set as follows:

$$
\begin{aligned}
& \frac{R(0.86 \mu \mathrm{m})}{R(0.65 \mu \mathrm{m})}<1.25 \\
& \frac{R(0.86 \mu \mathrm{m})}{R(1.24 \mu \mathrm{m})}<1.3
\end{aligned}
$$

These thresholds were empirically derived on the basis of case studies; however our forward simulations indicate that a parameterization based on ecosystem type may be more appropriate in the future. We will investigate such parameterization in MODIS data for collection 6 .

In addition to the precipitable water difference, another test is based on retrievals of 
cloud thermodynamic phase from two different methods. The first method is the MODIS SWIR thermodynamic phase (SP) algorithm (Platnick et al. 2003) that uses a number of cloud mask tests and reflectance ratios in visible, NIR and SWIR bands to arrive at cloud thermodynamic phase. The second method is the IR bi-spectral cloud phase (IP) algorithm based on brightness temperature differences between 8.5 and $11 \mu \mathrm{m}$ bands, which is a modification of the Baum IR tri-spectral algorithm (Baum et al. 2000). When these two methods infer different thermodynamic phases, that can be an indication of a multilayered cloud situation. This particular test tends to be sensitive to cirrus over liquid water clouds in which thin cirrus is too thin to result in an ice phase retrieval, but still biases the liquid water cloud retrievals as the cloud effective radius retrieval is larger than expected.

The main uncertainty associated with using the thermodynamic phase test tends to arise in polar regions. At latitudes above $60^{\circ}$, the IR method results in quite a few undetermined phase answers due to inherent difficulties of an IR method over very cold surfaces, so we assign a lower degree of confidence to multilayered clouds that are flagged only by the cloud phase test and no other test.

The $0.94 \mu \mathrm{m}$ precipitable water retrieval performed at both pressure at cloud top and at $900 \mathrm{mb}$, together with a test on retrieved cloud thermodynamic phase combine to create a final integer answer that tells the user whether the multilayer detection algorithm arrived at a positive result and what method(s) were positive as shown in Table 1 . We store the final value in the MOD06/MYD06 Level-2 HDF file in two places. The values from table 1 are stored in a Scientific Data Set (SDS) named Cloud_Multi_Layer_Flag. The multilayer cloud information is also stored in the $5^{\text {th }}$ byte of the Quality_Assurance_1 km SDS as information about the thermodynamic phase of the cloud and its multilayer status. The full description of the Quality_Assurance_1 km SDS is given in Hubanks (2006) and a brief listing of relevant values is given in table 2. 
The discussion in this section is summarized in Figure 3. The algorithm flow chart shows the overall logical flow of the algorithm.

\section{Radiative transfer models}

We have conducted an extensive set of forward RT modeling studies of multilayer clouds under varying atmospheric conditions, layer separations, surface types and layer thicknesses to thoroughly test the sensitivities and skill of the MODIS multilayer cloud detection algorithm.

Zonal and temporal average profiles are calculated from the ECMWF sampled 60level global atmospheric profile database aggregated from ERA-40 data over 48 days for two years using 1st and 15th of each month between January 1992 and December of 1993 (Chevallier, 2001). The database profiles were separated to represent a typical midlatitude summer (MLS), midlatitude winter (MLW), tropical atmosphere (TRP), and polar oceanic (POL) profile. Profiles over polar landmasses, dominated by profiles from the Antarctic continent, were not included as they would contain strong inversions and would be likely used disproportionately for pressures lower than $700 \mathrm{hPa}$. The polar oceanic profile consists of daytime profiles only. Nighttime profiles are not used since for our purposes, cloud optical and microphysical property retrievals are performed in daytime only. We define the tropical region as $30^{\circ} \mathrm{S}<$ latitude $<30^{\circ} \mathrm{N}$, midlatitudes as $30^{\circ}<$ $\mid$ latitude $\mid<60^{\circ}$ and the polar regions as above $60^{\circ}$ latitude. For midlatitudes, winter profiles occur between 1 November and 30 April; summer profiles are the remainder of the year. Within each latitude belt, profiles are chosen from regions that had cloud fraction (CF) $>0.85$ to match the conditions of interest. Profiles were separated further by land and ocean using the ECMWF land fraction flag with threshold set at 0.5 .

Given these averaged profiles, chosen levels were saturated with cloud having an appropriate cloud thermodynamic phase by setting relative humidity at levels that were chosen to contain cloud to $100 \%$. The profiles were interpolated from the native 60 -level 
resolution to 36 levels spaced at $1 \mathrm{~km}$ vertically between 0 and $25 \mathrm{~km}$ with sparser resolution in the upper atmosphere.

Figure 4 shows a combined plot of the temperature and moisture profiles used in the simulations. These particular plots show the liquid water cloud layer at $2 \mathrm{~km}$. Simulations were run for a variety of solar and view zenith angles with the solar zenith angles appropriate for the time of year in question. We sampled the solar zenith angle from the MODIS Level-3 global monthly product (Hubanks et al. 2008). The cosine of the view zenith angle corresponded to $\mu=1.0,0.8$ and 0.6 . For detailed examination, simulations were run for ice cloud effective radii of 10,30 and $50 \mu \mathrm{m}$ and water radii of 6,10 and 20 $\mu \mathrm{m}$. An ice cloud layer of $2 \mathrm{~km}$ physical thickness was fixed at the base of the tropopause as indicated by temperature in each of the different profiles shown in Figure 4: $8 \mathrm{~km}$ (MLW and POL), $12 \mathrm{~km}$ (MLS) and $14 \mathrm{~km}$ (TRP). The ice cloud optical thickness varied between 0 and 20 , with increments as follows: $0.0,0.1,0.25,0.5,1.0,2.0,3.0,4.0$, $5.0,6.0,7.0,8.0,10.0,20.0$. These increments were chosen specifically to examine the thin cirrus region and also to appropriately capture the point where the ice cloud becomes too thick to be affected by the underlying liquid water cloud. Water cloud layers were assumed to be $1 \mathrm{~km}$ thick and were placed at two different altitudes: $2 \mathrm{~km}$ and $4 \mathrm{~km}$. For liquid water clouds, optical thicknesses ranged as follows: $0.0,2.0,5.0,10.0,20.0$.

Radiances were simulated for 16 MODIS bands, which was necessary to perform the relevant cloud mask tests (Ackerman et al. 2006; Frey et al. 2008), in particular the 3.7$11 \mu \mathrm{m}$ brightness temperature test, the $\mathrm{CO}_{2}$ slicing cloud top properties retrieval, and the full MODIS cloud optical and microphysical property retrievals. The set included MODIS bands 1, 2, 5, 6, 7, 19, 20, 22, 26, 29, 31, 32, 33, 34, 35 and 36 (Ackerman et al. 2006).

Each simulation was repeated over a wide variety of surfaces. The oceanic profiles only had one option (dark ocean with surface albedo of 0.05 ) with the exception of polar 
ocean that also included a sea ice surface. The land surface profiles presented options of vegetated, desert, or snow cover. Midlatitude land included mixed forest and desert with or without snow, appropriately, while tropical land included desert and evergreen broadleaf forest. All classifications were based on definitions of the IGBP ecosystem map and the surface albedo values taken from MOD43-based 1-km resolution surface albedo product (Moody et al. 2005, 2007, 2008). Figure 5 shows a plot of the white-sky (diffuse) surface albedo as a function of wavelength for the various surfaces considered in this investigation. MODIS bands that contain no solar component were given a zero surface albedo.

The RT simulations were performed using DISORT (DIScrete Ordinate Radiative Transfer) code (Stamnes et al. 1988) using liquid water cloud phase function results from Mie calculations based on the water droplet size distributions using a gamma distribution with an effective variance of 0.1 (Platnick et al. 2003) and bulk ice cloud phase functions developed by Baum et al. (2005a,b). The same phase functions for both ice and liquid water are used in the LUTs employed in the MODIS cloud optical and microphysical properties algorithm for collection 5. The correlated- $k$ method (Kratz, 1995) was used to account for water vapor and other gaseous absorbers. The DISORT code, in conjunction with the correlated- $k$ method, then produced the simulated MODIS band radiances. We used 32 streams in our radiative transfer calculations, which, together with truncation of strong forward peaks and use of delta-fit method by Hu et al. (2000), can be considered sufficient computational accuracy as described by Ding et al. (2009).

With the parameter ranges described above, the forward RT calculations resulted in 26 files corresponding to combinations of atmospheric profiles and surface types. Each file contained 7560 individual data points for each geometry, optical thickness and effective radius tested. Results are provided in the following section for application of the MODIS multilayer cloud detection algorithm to a cross-section of this database of 
simulated MODIS radiances. In section 5 similar results are provided for the PavolonisHeidinger and Nasiri-Baum algorithms to this same dataset with comparison to the results from the MODIS operational algorithm.

\section{Results}

In this section we show results of applying the MODIS multilayer cloud retrieval simulated MODIS data. We show the results from a cross-section of our forward RT simulations. Figure 6 shows a set of combined results from the DISORT forward simulations. To facilitate the interpretation of results, we group individual runs having all but one identical parameters to illustrate the effect of the differing parameter on the multilayer cloud retrieval result. Figure 6 a combines the results of simulations conducted with a nadir view, solar zenith at $32^{\circ}$, dark ocean surface and liquid water cloud located at an altitude of $2 \mathrm{~km}$. The atmospheric profile is varied in terms of the overall column moisture content. The plot in Figure 6 a effectively shows multilayer cloud detection as a function of the total column water vapor. The 'bits' in the effective binary numbers that result from this data combination indicate whether or not a multilayer cloud was detected. The bit significance was arranged as a function of the column moisture with the least significant bit for the most moisture. For example, a value of 011 , which is light green in the plot, means that a multilayer cloud was detected under the conditions specified above using TRP and MLS profiles, but no multilayer cloud was detected for the MLW profile. The algorithm is more likely to detect a multilayer situation when the ice cloud is optically thin if the atmospheric moisture content is higher.

Figure $6 \mathrm{~b}$ shows the same basic situation as Figure $6 \mathrm{a}$ with the exception that the altitude of the lower-layer liquid water cloud was placed at $4 \mathrm{~km}$ and thus decreases the cloud layer separation. When the cloud layer separation is smaller, the amount of atmospheric water vapor between the two cloud layers is also lower and so the absorption in the $0.94 \mu \mathrm{m}$ channel is decreased over the previous case. The sensitivity of the algorithm de- 
creases as the ice optical thickness increases compared to the case where the liquid water cloud is at $2 \mathrm{~km}$ altitude. Some false positives occur in which multilayer cloud is detected for thicker liquid water clouds where there is no ice cloud above. These false positives come from growing uncertainties in retrieving IR cloud phase and $\mathrm{CO}_{2}$ cloud top properties as the cloud gets colder. The detection results can be inspected further by looking at individual tests, some of which have lower confidence than others as mentioned in section 2 . The detection status is reported as a binary answer and may result in a false positive result.

Figure 6c illustrates the multilayer detection result as a function of underlying surface type, assuming a single MLS profile and a liquid water cloud placed at $2 \mathrm{~km}$ altitude. The surface types are arranged such that the least significant bit corresponds to the lowest overall surface albedo with no snow on the ground. The plot shows that multilayered clouds are not detected for a desert ecosystem with thin liquid water clouds below, since the liquid cloud emissivity is likely somewhat less than 1.0 , thereby indicating that we may need a separate detection threshold for deserts since the surface albedo of deserts is significantly different in spectral shape from vegetation and snow/ice surfaces. The desert spectral albedo tends to be somewhat flatter than vegetation, as Figure 5 shows, and so may require a somewhat different approach. The effect of this on our global statistics is not very significant as the actual cloud fraction over deserts is rather low (cf. Figure 9). Figure $6 \mathrm{~d}$ shows multilayered cloud detection as a function of cosine of the viewing zenith angle $(\mu)$ for a MLS profile with a dark ocean surface and a lower-layer liquid water cloud placed at $2 \mathrm{~km}$. The points are ordered in $\mu$-space such that a more oblique angle, i.e., lower $\mu$, is the least significant bit in the binary number displayed. The relative azimuth angle for this comparison was set to $0^{\circ}$. The figure indicates that the algorithm is more likely to detect a thinner ice cloud over a liquid water cloud at more oblique angles. On the other hand, it is possible to flag cases with higher ice cloud optical thicknesses at 
more nadir view angles.

The Pavolonis-Heidinger method, originally developed for the AVHRR and adapted for the upcoming VIIRS instrument, uses a series of reflectance and brightness temperature difference thresholds described in detail in (Pavolonis et al. 2004). For the algorithm comparison purposes we have been provided with their most recent development of the method, with improvements and modifications made since the publication of their paper. Similar to the MODIS operational algorithm, it is a single-pixel method that works on samples individually without using any spatial aggregation. Because of this similarity we were able to execute the Pavolonis-Heidinger algorithm on the results of our DISORT simulations of multilayer clouds. Figure 7 shows the comparison of these results. The figures on the left are the MODIS results from Figure $6 \mathrm{a}, 6 \mathrm{~b}$ and $6 \mathrm{~d}$, and on the right are corresponding Pavolonis-Heidinger results. We compared the algorithms for three out of four database cross-sections shown in Figure 6. It was not possible to perform the exact comparison for the surface-type section, since the Pavolonis-Heidinger algorithm uses a $0.41 \mu \mathrm{m}$ band over desert regions that we did not include in the original DISORT band set. The Pavolonis-Heidinger algorithm uses a lookup table (LUT) derived from simulations of multilayered clouds over a various surfaces. The LUT includes the difference in brightness temperatures (BTD) between the 11 and $12 \mu \mathrm{m}$ bands. A threshold function is defined since the multilayered clouds (i.e., ice over water cloud) display a BTD as a function of visible reflectance that is quite different from single-layered liquid water and ice clouds. In addition to that threshold, a number of constraints are placed on reflectances at 0.65 and $1.38 \mu \mathrm{m}$ to help with the identification of single layer clouds over a variety of surfaces. The $1.65 \mu \mathrm{m}$ band is used by the algorithm to aid in identifying the thermodynamic phase of clouds since ice clouds have greater absorption than liquid water clouds at $1.65 \mu \mathrm{m}$.

There are similarities in the results as well as some differences, but overall the com- 
parison is favorable. The MODIS algorithm has a somewhat wider section where multilayer clouds are detected for the entire range of the varied conditions, be it atmospheric moisture content or view angle. However the detection rate generally drops off as the ice cloud thickens with only the thickest simulated liquid water cloud showing at ice cloud optical thickness of 10. Both algorithms show that once the ice cloud optical thickness reaches 20 , no detection of multilayer clouds is possible. Both algorithms also show that detection is a function of layer separation with detection rate being lower when the liquid water cloud is placed at $4 \mathrm{~km}$ as opposed to $2 \mathrm{~km}$ cloud top altitude. The PavolonisHeidinger algorithm shows more detection when both cloud layers thicken, but not as much when the cloud layers are thin.

We could not run the Nasiri-Baum algorithm on DISORT simulations because it is a statistical aggregate algorithm that depends on natural variability of the data within a given area. More specifically, the algorithm uses a brightness temperature difference between 8.5 and $11 \mu \mathrm{m}$ to confidently determine the clouds that are liquid water phase. Liquid water clouds tend to have a large, negative brightness temperature difference. The data are analyzed on $200 \times 200$ pixel tiles that must meet a number of conditions to attempt the retrieval. The tile must contain clouds and must contain at least 10 pixels each of ice cloud, liquid water cloud, and clear sky. Additionally, a scatter plot of $11-\mu \mathrm{m}$ brightness temperature versus the $2.1 \mu \mathrm{m}$ reflectance is created, wherein pixels that belong to single layer ice clouds and single layer liquid water clouds create two distinct lines. The clear sky points lay on the intersection of those lines. The angle between the lines must be greater than $20^{\circ}$. The grid of tiles undergoes successive systematic shifts to increase the number of times a particular pixel is processed; the more times a pixel is flagged as multilayered, the higher the confidence of the final answer. As DISORT results are single points, there is no way to create an appropriate analysis box that would satisfy the data requirements of the Nasiri-Baum algorithm. 
Our overall conclusion from examining all these results is that the MODIS multilayer cloud detection algorithm is robust and performs as intended under a wide variety of conditions.

\section{Analysis and comparison with other methods}

In this section we show an example case study from MODIS and comparisons of our method against two other multilayer cloud detection algorithms, which we mentioned in section 1 .

Figure 8 shows an example of multilayer cloud detection for a Terra MODIS granule acquired on 25 October 2008 off the coast of Japan at 0015 UTC. This is a full granule, a portion of which was shown in Figure 1. Figure 8a shows an atmospherically corrected true color image formed as a composite of MODIS bands 1,4 , and $3(0.65,0.55$, and 0.47 $\mu \mathrm{m}$, respectively). While the false color image indicates where the clouds are, it provides very little information about the various cloud layers or the thermodynamic phase of the clouds. Figure $8 \mathrm{~b}$ shows a false color image formed as a composite of bands 6,2 , and 26 (1.64, 0.86 , and $1.38 \mu \mathrm{m}$, respectively), which more readily separates clouds of different thermodynamic phase by color. There is a significant amount of multilayer cloud in this scene, indicated by areas where the yellow liquid water clouds show through the more blue and white ice clouds. Figure $8 \mathrm{c}$ shows the results from applying the multilayer cloud detection algorithm. Different values on the color scale correspond to tests flagging the cloud as clear sky (0), single layer cloud (1), and multilayer (2-8) cloud, as described in Table 1. These results are not an absolute measure of multilayer cloud amount, but rather provide a map of areas where the presence of multilayer clouds adversely affects cloud effective radius retrievals.

In Collection 5, MODIS multilayer cloud retrievals are aggregated to the global level-3 daily, eight-day, and monthly products as an average of data down-sampled to 5 $\mathrm{km}$ and aggregated into a $1^{\circ}$ grid. The multilayer cloud fraction is stored, combined and 
separated by thermodynamic phase, and also includes mean values of cloud optical and microphysical properties retrievals, both with and without multilayer clouds. (Hubanks et al. 2008). Figure 9 shows an example of such an aggregation for the month of October 2008 derived from Terra MODIS data. Figure 9a shows the fraction of all cloudy pixels that have the multilayer flag set, and Figure $9 \mathrm{~b}$ shows the mean monthly cloud fraction. The small black area on the very top of the images corresponds to polar darkness or low sun where no retrievals are attempted (cosine of the solar zenith angle $\mu_{0}<0.15$ ).

A monthly global map like this is useful for providing the spatial distribution of multilayered clouds. Based on observational evidence, one might expect a higher frequency of multilayered clouds to occur in the vicinity of low-pressure systems and their frontal boundaries. Higher frequencies of multilayer clouds tend to occur in the Southern Ocean and in the storm tracks (higher latitude zones) of both hemispheres. Tropical anvil cirrus is also a likely candidate to create multilayer cloud situations. A good portion of the Intertropical convergence zone (ITCZ) is flagged as multilayer in the eastern Pacific Ocean. Strong convective zones over rainforest areas also tend to generate anvil cirrus, resulting in high frequencies of multilayered clouds in the Congo basin, Borneo, and New Guinea. One can also note the effect of advection of anvil cirrus over the marine stratocumulus zones in the Southern Hemisphere off the coasts of Peru and Ecuador, and in the Gulf of Guinea.

The three multilayer cloud detection algorithms previously discussed are now applied to the MODIS granule shown in Fig. 8, with the results shown in Figure 10. Figure 10a shows the true color composite constructed from bands at $0.65,0.55$, and $0.47 \mu \mathrm{m}$, Figure $10 \mathrm{~b}$ the false color composite constructed from bands at $1.64,0.86$, and $1.38 \mu \mathrm{m}$, and Figure 10c the false color composite constructed from bands at $0.55,1.64$, and 2.13 $\mu \mathrm{m}$. Figures 10d-f show the results of applying the multilayer cloud detection using the d) MODIS operational algorithm, e) Pavolonis-Heidinger algorithm, and f) Nasiri-Baum 
algorithm.

As there is a wide range of options, described in the code documentation, that the Nasiri-Baum algorithm can be executed under, for the purposes of this comparison we took the suggested default values. The Nasiri-Baum algorithm can only be executed under conditions that some clear sky, liquid water cloud and ice cloud exists within the box being currently analyzed, so the algorithm does not attempt retrievals over a portion of this granule. The Nasiri-Baum algorithm also outputs its result as a probability of multilayer cloud being present. For clarity we display only a non-zero overlap probability as a positive answer. We performed a similar procedure with the results from the MODIS operational multilayer cloud algorithm, combining the multilayer values $2-8$ into a single positive identification value. The Pavolonis-Heidinger algorithm returns its result as a single value so no additional data conversion was necessary to visualize the results.

Overall many of the same areas flagged as multilayer, even though the results may not look exactly the same, as the different multilayer algorithms were developed with different applications in mind. The Nasiri-Baum algorithm gives the fewest multilayer occurrences, but that can be attributed to a limited area over which the algorithm attempts retrievals. The main disagreement between Pavolonis-Heidinger and our algorithm arises in the flagging of thicker high clouds as being part of multilayer scenes (e.g., left side portion of the granule). One might argue that most, if not all, ice phase clouds in that part of the granule are multilayered clouds because of the apparent wide presence of low clouds in that region as well as there being some indication in the $1.38 \mu \mathrm{m}$ false color composite. The result given by the Pavolonis-Heidinger algorithm is consistent with detection achieved for simulated DISORT data, where clouds with combined extinction optical thickness as large as 30 , with the upper layer thickness of 10 , can be flagged as multilayer, as shown in Figure 7.

The decision whether to flag a cloud as multilayer depends on the issue being ad- 
dressed. In our case, we are looking for multilayer clouds that challenge the applicability of our single-layer plane-parallel cloud models used in cloud optical and microphysical property retrievals. Our goal is to create a map of areas where the model application is problematic. From our RT simulations we have found that the effect of ice cloud overlapping a liquid water cloud on cloud effective radius retrieval diminishes quite rapidly with increasing ice cloud optical thickness and is barely detectable when ice cloud optical thickness becomes greater than about 6 . While it may be the case that the thicker upper level clouds in this granule are also multilayer, having those clouds flagged as such does not impact our primary objective regarding microphysical biases.

Joiner et al. have provided initial comparisons of the MODIS multilayer cloud detection algorithm to CloudSat/CALIPSO as part of a study which developed a multilayer detection algorithm via OMI-derived cloud-top pressure (UV rotational-Raman scattering) compared with MODIS thermal emission retrievals. The OMI approach is philosophically similar to the MODIS approach reported here in that both take advantage of solar reflectance path lengths being affected by gas species between cloud layers $\left(\mathrm{O}_{2}\right.$ for OMI, water vapor in this study) in a fundamentally different way than $\mathrm{CO}_{2}$ slicing spectral bands; an $\mathrm{O}_{2}$ method of course have the advantage of being a well-mixed gas (see Fig. 6a, b). With multilayer detection from CloudSat defined as layer separations greater than $200 \mathrm{hPa}$, global analyses from a single day in Joiner et al. found that the MODIS algorithm correctly identified single and multilayer cloud layers $83.4 \%$ of the time, with false positives and negatives, $9.8 \%$ and $6.8 \%$ of the time, respectively. However, the MODIS algorithm is sensitive to upper layer cirrus optical thicknesses on the order of 0.2 (Figs 6 , 7). False positives from missed thin cirrus are not considered in the Joiner et al. study. As already noted, the MODIS algorithm was intended to flag cases where upper layer clouds have optical thicknesses too small to significantly screen lower level clouds in the short wave infrared bands used for particle size retrievals; such cases were not considered in 
assessing false negatives. For both types of false detection, information from CALIPSO cirrus optical thickness retrievals are needed, as well as monthly and seasonal comparisons (vs. single day).

\section{Conclusions and future directions}

In this paper we present the MODIS operational multilayer cloud detection algorithm used in the MODIS collection 5 cloud optical and microphysical properties product (MOD06 for Terra, MYD06 for Aqua). The multilayer cloud detection method was developed to address a need to indicate areas of cloud where an assumption of single-layer plane-parallel cloud models was challenged due to the presence of two distinct cloud layers with differing thermodynamic phases, with the upper cloud layer being optically thin. Such situations manifest themselves as areas of abnormal cloud effective radius retrievals. Our method uses the difference between retrieved above-cloud precipitable water amounts from the $0.94 \mu \mathrm{m}$ band and from the $\mathrm{CO}_{2}$ slicing cloud top height, together with a number of other tests. The physical basis of the multilayered cloud detection algorithm is provided, with examples of results from forward simulations as well as case studies involving MODIS data and global aggregations of results. Results from this approach are compared to two other methods of multilayer cloud detection. We also present a set of standard cloudy atmospheres that we developed to perform our studies. Wherever possible we perform all comparisons using a single source dataset, so the differences in retrieved results are solely due to differences in methodology.

Our results and analysis indicate that the multilayer cloud detection algorithm presents a reliable means of identifying situations that would create difficulties for retrievals of cloud effective radius. The forward simulations indicate that there are very few falsepositive results and that they arise under conditions that would result in high retrieval uncertainty due to one of the cloud layers being extremely thin. Forward radiative transfer simulations, performed under a wide variety of surface and atmospheric conditions, are 
used in our analyses to provide further insight as to the robustness of the algorithm.

We are currently investigating a number of improvements for the MODIS operational multilayer cloud detection algorithm that may be implemented for MODIS collection 6. Those improvements involve bringing in additional retrievals of physical quantities performed using different methods, which in our experience has shown to contain multilayer cloud information. We also intend to continue our ongoing comparisons by performing more extensive MODIS to CALIPSO comparisons. However for that work we require more data products than what is currently available from CALIPSO. We have begun such studies (R. Holz, private communication) and are awaiting the next release of CALIPSO products (Version 3).

\section{Acknowledgments}

The authors would like to thank Brad Wind for developing the groundwork for simplifying the modifications to the operational MODIS code that made most of these studies possible. This work was funded by the MODIS Science Team and NASA's Radiation Sciences Program. 


\section{REFERENCES}

Ackerman, A., K. Strabala, P. Menzel, R. Frey, C. Moeller, L. Gumley, B. Baum, S. W. Seemann, and H. Zhang, 2006: Discriminating clear-sky from cloud with MODIS Algorithm Theoretical Basis Document (MOD35). ATBD Reference Number: ATBD-MOD-06. modis-atmos.gsfc.nasa.gov/reference atbd.php.

Barnes, W. L., T. S. Pagano, and V. V. Salomonson, 1998: Prelaunch characteristics of the Moderate Resolution Imaging Spectroradiometer (MODIS) on EOS-AM1. IEEE Trans. Geosci. Remote Sens., 36, 088-1100.

Baum, B. A., and J. D. Spinhirne, 2000: Remote sensing of cloud properties using MODIS Airborne Simulator imagery during SUCCESS. III. Cloud overlap. J. Geophys. Res., 105, 11793-11804.

, A. J. Heymsfield, P. Yang, and S. T. Bedka, 2005a: Bulk scattering models for the remote sensing of ice clouds. Part 1: Microphysical data and models. J. Appl. Meteor., 44, 1885-1895.

, P. F. Soulen, K. I. Strabala, M. D. King, S. A. Ackerman, W. P. Menzel, and P. Yang, 2000: Remote sensing of cloud properties using MODIS airborne simulator imagery during SUCCESS. II. Cloud thermodynamic phase. J. Geophys. Res., 105, $11781-11792$.

, P. Yang, A. J. Heymsfield, S. Platnick, M. D. King, Y. X. Hu, and S. T. Bedka, 2005b: Bulk scattering models for the remote sensing of ice clouds. Part 2: Narrowband models. J. Appl. Meteor., 44, 1896-1911.

Bedka, S. T., W. F. Feltz, A. J. Schreiner, and R. E. Holz, 2007: Satellite-derived cloud top pressure product validation using aircraft-based cloud physics lidar data from the ATReC field campaign. Int. J. Remote Sens., 28, 2221-2239.

Berk A., L. S. Bernstein, G. P. Anderson, P. K. Acharya, D. C. Robertson, J. H. Chetwynd, and S. M. Adler-Golden 1998: MODTRAN cloud and multiple scattering up- 
grades with application to AVIRIS. Remote Sens. Environ., 65, 367-375.

Chang, F. L., and Z. Li, 2005: A new method for detection of cirrus overlapping water clouds and determination of their optical properties. J. Atmos. Sci., 62, 3993-4009. , and , 2005: A near-global climatology of single-layer and overlapped clouds and their optical properties retrieved from Terra/MODIS data using a new algorithm. J. Climate, 18, 4752-4771.

Chevallier, F. 2001: Sampled databases of 60-level atmospheric profiles from the ECMWF analyses. SAF program, Research report \#4.

Chiriaco, M., H. Chepfer, P. Minnis, M. Haeffelin, S. Platnick, D. Baumgardner, P. Dubuisson, M. McGill, V. Noel, J. Pelon, D. Spangenberg, S. Sun-Mack, and G. Wind, 2007: Comparison of CALIPSO-like, LaRC and MODIS retrievals of ice cloud properties over SIRTA in France and Florida during CRYSTAL-FACE. J. Appl. Meteor. Climatol., 46, 249-272.

Davis, S. M., L. M. Avallone, B. H. Kahn, K. G. Meyer, and D. Baumgardner, 2009: Comparison of airborne in situ measurements and Moderate Resolution Imaging Spectroradiometer (MODIS) retrievals of cirrus cloud optical and microphysical properties during the Midlatitude Cirrus Experiment (MidCiX), J. Geophys. Res., 114, D02203, doi:10.1029/2008JD010284.

Ding, S., Y. Xie, P. Yang, F. Weng, Q. Liu, B. Baum, Y. Hu, 2009: Estimates of radiation over clouds and dust aerosols: Optimized number of terms in phase function expansion. JQSRT, 110, 1190-1198

Frey, R. A., S. A. Ackerman, Y. Liu, K. I. Strabala, H. Zhang, J. R. Key, and X. Wang, 2007: Cloud detection with MODIS. Part I: Improvements in the MODIS cloud mask for collection 5. J. Atmos. Oceanic Tech., 25, 1057-1072.

Hu, Y.-X., B. Wielicki, B. Lin, G. Gibson, S.-C. Tsay, K. Stamnes, T. Wong, 2000: $\delta$-Fit: A fast and accurate treatment of particle scattering phase functions with weighted 
singular-value decomposition least-squares fitting. JQSRT, 65, 681-690

Hubanks, P. A. 2006: MODIS Atmosphere QA Plan for Collection 005. Available from modis-atmos.gsfc.nasa.gov/MOD08_M3/atbd.html.

, M. D. King, S. A. Platnick, and R. A. Pincus, 2008: MODIS Atmosphere L3 Gridded Product Algorithm Theoretical Basis Document. ATBD Reference Number: ATBD-MOD-30. Available from modisatmos.gsfc.nasa.gov/MOD08_M3/atbd.html.

Joiner, J., A.P. Vasilkov, P.K. Bhartia, G. Wind, S. Platnick and W.P. Menzel, 2010: Detection of multi-layer and vertically-extended clouds using A-train sensors. Atmos. Meas. Tech., 3, 233-247.

King, M. D., W. P. Menzel, Y. J. Kaufman, D. Tanré, B. C. Gao, S. Platnick, S. A. Ackerman, L. A. Remer, R. Pincus, and P. A. Hubanks, 2003: Cloud and aerosol properties, precipitable water, and profiles of temperature and humidity from MODIS. IEEE Trans. Geosci. Remote Sens., 41, 442-458.

, S. Platnick, P. Yang, G. T. Arnold, M. A. Gray, J. C. Riedi, S. A. Ackerman, and K. N. Liou, 2004: Remote sensing of liquid water and ice cloud optical thickness, and effective radius in the arctic: Application of airborne multispectral MAS data. $J$. Atmos. Oceanic Technol., 21, 857-875.

Kratz, D. P., 1995: The correlated k-distribution technique as applied to the AVHRR channels. J. Quant. Spectrosc. Radiat. Transfer, 53, 501-517.

Mace, G. G., Y. Zhang, S. Platnick, M. D. King, P. Minnis, and P. Yang, 2005: Evaluation of cirrus cloud properties derived from MODIS data using cloud properties derived from ground-based observations collected at the ARM SGP site. J. Appl. Meteor., 44, 221-240.

Menzel, W. P., R. Frey, H. Zhang, D. Wylie, C. Moeller, R. Holz, B. Maddux, B. A. Baum, K. Strabala, and L. Gumley, 2008: MODIS global cloud-top pressure and 
amount estimation: Algorithm description and results. J. Appl. Meteor. Climatol., 47, 1175-1198.

Moody, E. G., M. D. King, S. Platnick, C. B. Schaaf, and F. Gao, 2005: Spatially complete global spectral surface albedos: Value-added datasets derived from Terra MODIS land products. IEEE Trans. Geosci. Remote Sens., 43, 144-158.

, C. B. Schaaf, D. K. Hall, and S. Platnick, 2007: Northern Hemisphere fiveyear average (2000-2004) spectral albedos of surfaces in the presence of snow: Statistics computed from Terra MODIS land products. Remote Sens. Environ., 111, $337-345$.

, and S. Platnick, 2008: MODIS-derived spatially complete surface albedo products: Spatial and temporal pixel distribution and zonal averages. J. Appl. Meteor. Climatol., 47, 2879-2894.

Nasiri, S. L., and B. A. Baum, 2004: Daytime multilayered cloud detection using multispectral imager data. J. Atmos. Ocean. Technol., 21, 1145-1155.

Otkin, J. A., and T. J. Greenwald, 2008: Comparison of WRF model-simulated and MODIS-derived cloud data. Mon. Wea. Rev., 136, 1957-1970.

Pavolonis, M. J., and A. K. Heidinger, 2004: Daytime cloud overlap detection from AVHRR and VIIRS. J Appl. Meteor., 43, 762-778.

Platnick, S., M. D. King, S. A. Ackerman, W. P. Menzel, B. A. Baum, J. C. Riedi, and R. A. Frey, 2003: The MODIS cloud products: Algorithms and examples from Terra. IEEE Trans. Geosci. Remote Sens., 41, 459-473.

Stamnes, K., S. C. Tsay, W. Wiscombe, and K. Jayaweera, 1988: Numerically stable algorithm for discrete-ordinate-method radiative transfer in multiple scattering and emitting layered media. Appl. Opt. 27, 2502-2509. 


\section{TABLE LEGENDS}

TABLE 1.Listing of discrete values in SDS Cloud_Multi_Layer_Flag and definitions.

TABLE 2. Listing of discrete values in the $5^{\text {th }}$ byte of SDS Quality_Assurance_ $1 \mathrm{~km}$ and definitions. 
TABLE 1.Listing of discrete values in SDS Cloud_Multi_Layer_Flag and definitions.

\begin{tabular}{|c|l|}
\hline $\begin{array}{c}\text { Result } \\
\text { Value }\end{array}$ & Description \\
\hline 0 & Clear sky \\
\hline 1 & Single layer cloud or cloud too thin $\left(\tau_{c}<4\right)$ \\
\hline 2 & Multi-layer. Cloud phase test positive \\
\hline 3 & Multi-layer. Precipitable water with retrieved pressure test positive \\
\hline 4 & Multi-layer. Precipitable water with pressure fixed at $900 \mathrm{hPa}$ test positive \\
\hline 5 & Multi-layer. Both 3 and 4 \\
\hline 6 & Multi-layer. Both 2 and 3 \\
\hline 7 & Multi-layer. Both 2 and 4 \\
\hline 8 & Multi-layer. All three tests positive \\
\hline
\end{tabular}


TABLE 2. Listing of discrete values in the $5^{\text {th }}$ byte of SDS Quality_Assurance_ $1 \mathrm{~km}$ and definitions.

\begin{tabular}{|c|l|}
\hline $\begin{array}{c}\text { Result } \\
\text { Value }\end{array}$ & Description \\
\hline 0 & Cloud mask undetermined \\
\hline 1 & Not processed (typically clear) \\
\hline 2 & Single layer liquid water cloud \\
\hline 3 & Multilayer liquid water cloud \\
\hline 4 & Single layer ice cloud \\
\hline 5 & Multilayer ice cloud \\
\hline 6 & Single layer undetermined phase cloud \\
\hline 7 & Multilayer undetermined phase cloud \\
\hline
\end{tabular}




\section{FIGURE LEGENDS}

FIG. 1. Cloud and water vapor properties over the western Pacific Ocean off Japan as acquired by Terra MODIS on 25 October 2008 at 0015 UTC. Panel (a) is a false color composite of one MODIS granule, showing liquid water clouds in gold, ice clouds in blue and white, and overlapped clouds in green. Panels (b) and (c) show above cloud precipitable water derived from $\mathrm{CO}_{2}$ slicing and $0.94 \mu \mathrm{m}$ solar absorption, respectively. Panel (d) shows the difference in the derived PW from these two techniques. Panels (e) shows above cloud PW derived by assuming the reflecting lower cloud is located at $900 \mathrm{hPa}$ and (f) the difference in above-cloud PW from this result and $\mathrm{CO}_{2}$ slicing. Panels (g) and (h) show retrieved values of cloud optical thickness and effective radius for liquid water and ice clouds. Panel (i) shows results of the precipitable water multilayer tests. Areas of color indicate where the tests returned a positive answer. I.e. precipitable water difference was higher than $8 \%$ of the total column water vapor.

FIG. 2. Histograms of optical thickness and effective radius for ice clouds within the scene presented in Figure 1. The effective radius histogram shows a significant 'shoulder' of smaller effective radii when multilayer clouds are not removed from the scene. Those small effective radius retrievals come from the mixing of the strong liquid water cloud signal with a relatively weak cirrus signal.

FIG. 3. Flowchart for determining the presence of multilayer clouds using MODIS (collection 5).

FIG. 4. Vertical profiles of (a) temperature and (b) moisture used as a base in the forward models. The moisture profiles show saturation at levels that contain clouds. In this example the liquid water cloud is located at $2 \mathrm{~km}$ altitude and ice clouds are placed according to the tropopause location.

FIG. 5. White-sky albedo as a function of wavelength for selected IGBP ecosystem classifications used in the forward calculations. 
FIG. 6. MODIS multilayer cloud detection over various surfaces, water vapor content, and view zenith angle for a cross-section of DISORT simulations. . Water vapor profiles are mid-latitude summer (MLS), mid-latitude winter (MLW) and mean tropical (TRP). Panel (a) indicates the detection of multilayer clouds over ocean when the lower layer liquid water cloud is placed at $2 \mathrm{~km}$ altitude and panel (b) for a lower layer liquid water cloud placed at $4 \mathrm{~km}$ altitude. The color bar identifies the selection of multilayer clouds for various atmospheric profiles containing different water vapor profiles. Panel (c) shows the MODIS multilayer cloud detection over various surfaces including desert, forest, and snow. Panel (d) shows multilayer cloud detection for various view zenith directions.

FIG. 7. Results of MODIS (left) and Pavolonis-Heidinger (right) multilayer cloud detection for a cross-section of DISORT simulations. Panel (a) indicates the detection of multilayer clouds over ocean when the lower layer liquid water cloud is placed at $2 \mathrm{~km}$ altitude and panel (b) for a lower layer liquid water cloud placed at $4 \mathrm{~km}$ altitude. The color bar identifies the selection of multilayer clouds for various atmospheric profiles containing different water vapor profiles. Panel (c) shows multilayer cloud detection for various view zenith directions.

FIG. 8. Multilayer cloud over the western Pacific Ocean off Japan on 25 October 2008. Panel (a) is a true color composite of a Terra MODIS granule at 0015 UTC. Gray box indicates the area of interest presented in Figure 1. Panel (b) is a false color composite that more clearly shows the liquid water clouds (gold), ice clouds (blue) and multilayer clouds (green). Panel (c) is the multilayer cloud SDS that shows clear sky (0), single layer clouds (1), and multilayer clouds determined by various algorithm choices (2-8) (see Table 1).

FIG. 9. Terra MODIS monthly level-3 global product for October 2008. Panel (a) shows the fraction of cloudy pixels with multilayer cloud flag identified (all 
phases), and panel (b) shows the combined cloud fraction.

FIG. 10. Multilayer cloud analysis and cloud optical properties over the western Pacific Ocean off Japan as acquired by Terra MODIS on 25 October 2008 at 0015 UTC. Panel (a) is a true color composite of one MODIS granule and panel (b) is a false color composite, showing liquid water clouds in gold, ice clouds in blue and white, and overlapped clouds in green. Panel (c) is another false color composite showing ice clouds in pink and liquid clouds in blue. Panels (d), (e), and (f) show multilayer cloud identification using the MODIS collection 5, Pavolonis-Heidinger, and Nasiri-Baum algorithms, respectively. Panels (g) and (h) show retrieved values of cloud optical thickness and effective radius for liquid water and ice clouds. 

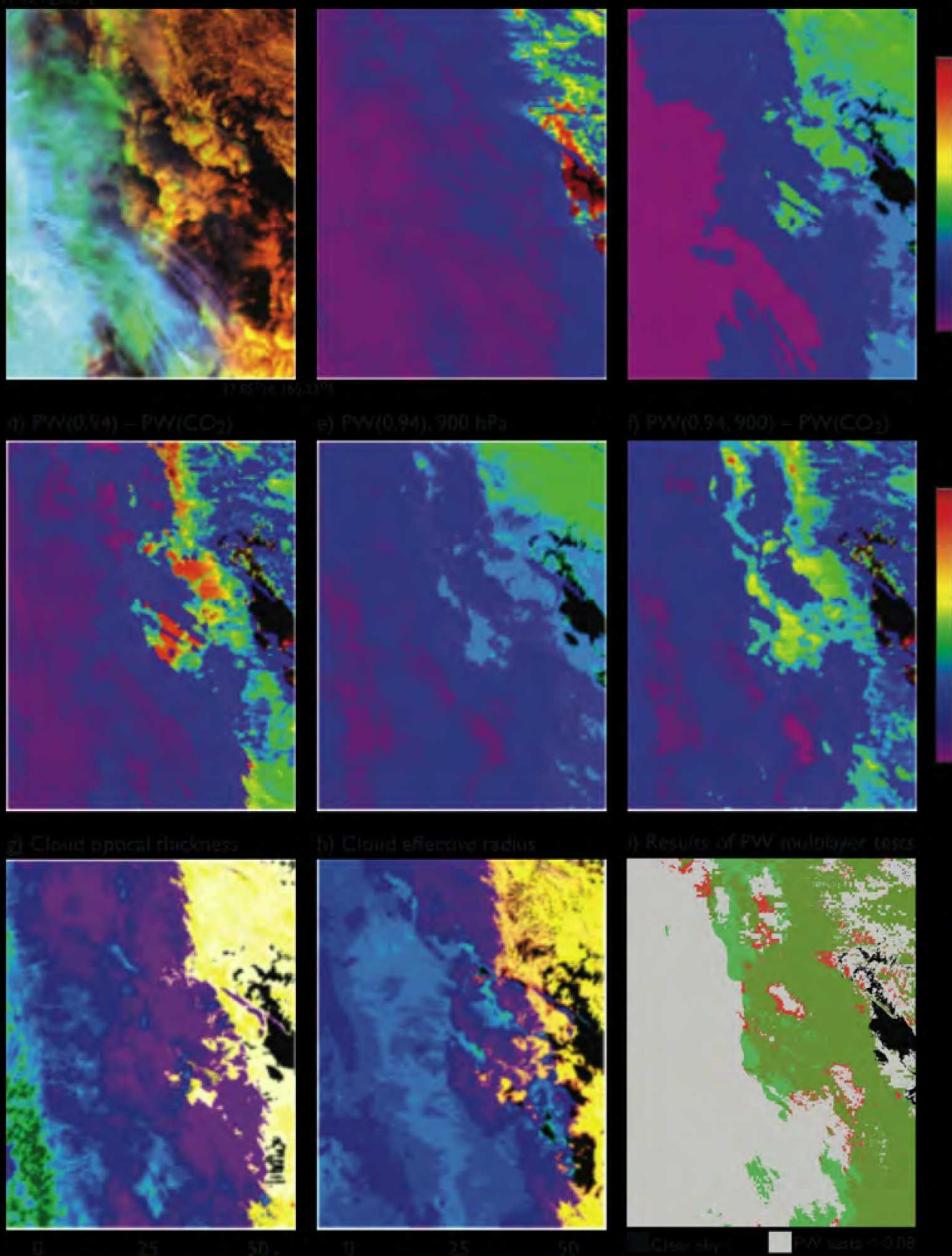

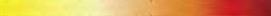

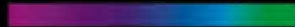

$\square$

FIG. 1. Cloud and water vapor properties over the western Pacific Ocean off Japan as acquired by Terra MODIS on 25 October 2008 at 0015 UTC. Panel (a) is a false 
color composite of one MODIS granule, showing liquid water clouds in gold, ice clouds in blue and white, and overlapped clouds in green. Panels (b) and (c) show above cloud precipitable water derived from $\mathrm{CO}_{2}$ slicing and $0.94 \mu \mathrm{m}$ solar absorption, respectively. Panel (d) shows the difference in the derived PW from these two techniques. Panels (e) shows above cloud PW derived by assuming the reflecting lower cloud is located at $900 \mathrm{hPa}$ and (f) the difference in above-cloud PW from this result and $\mathrm{CO}_{2}$ slicing. Panels $(\mathrm{g})$ and (h) show retrieved values of cloud optical thickness and effective radius for liquid water and ice clouds. Panel (i) shows results of the precipitable water multilayer tests. Areas of color indicate where the tests returned a positive answer. I.e. precipitable water difference was higher than $8 \%$ of the total column water vapor. 

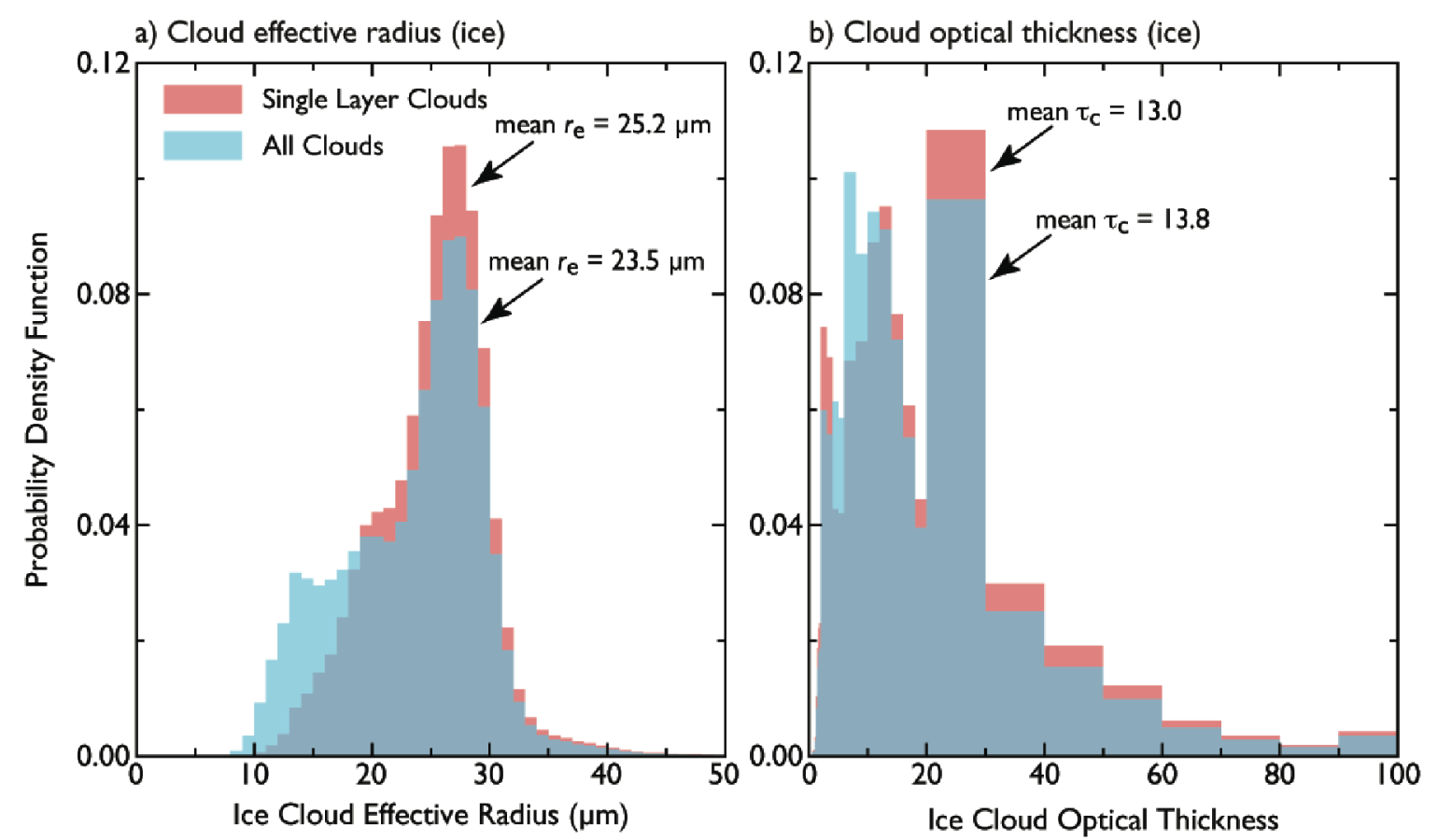

FIG. 2. Histograms of optical thickness and effective radius for ice clouds within the scene presented in Figure 1. The effective radius histogram shows a significant 'shoulder' of smaller effective radii when multilayer clouds are not removed from the scene. Those small effective radius retrievals come from the mixing of the strong liquid water cloud signal with a relatively weak cirrus signal. 


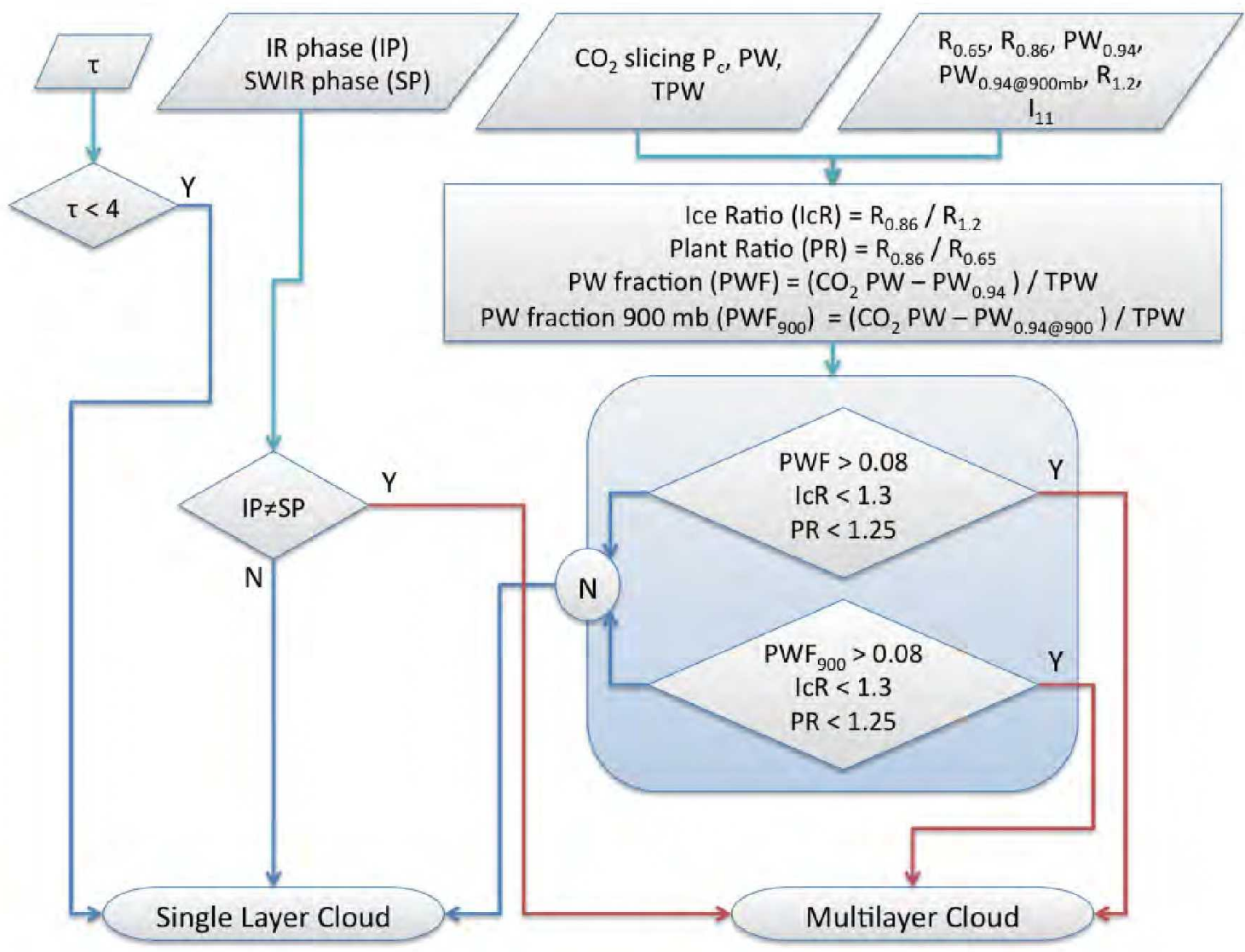

FIG. 3. Flowchart for determining the presence of multilayer clouds using MODIS (collection 5). 

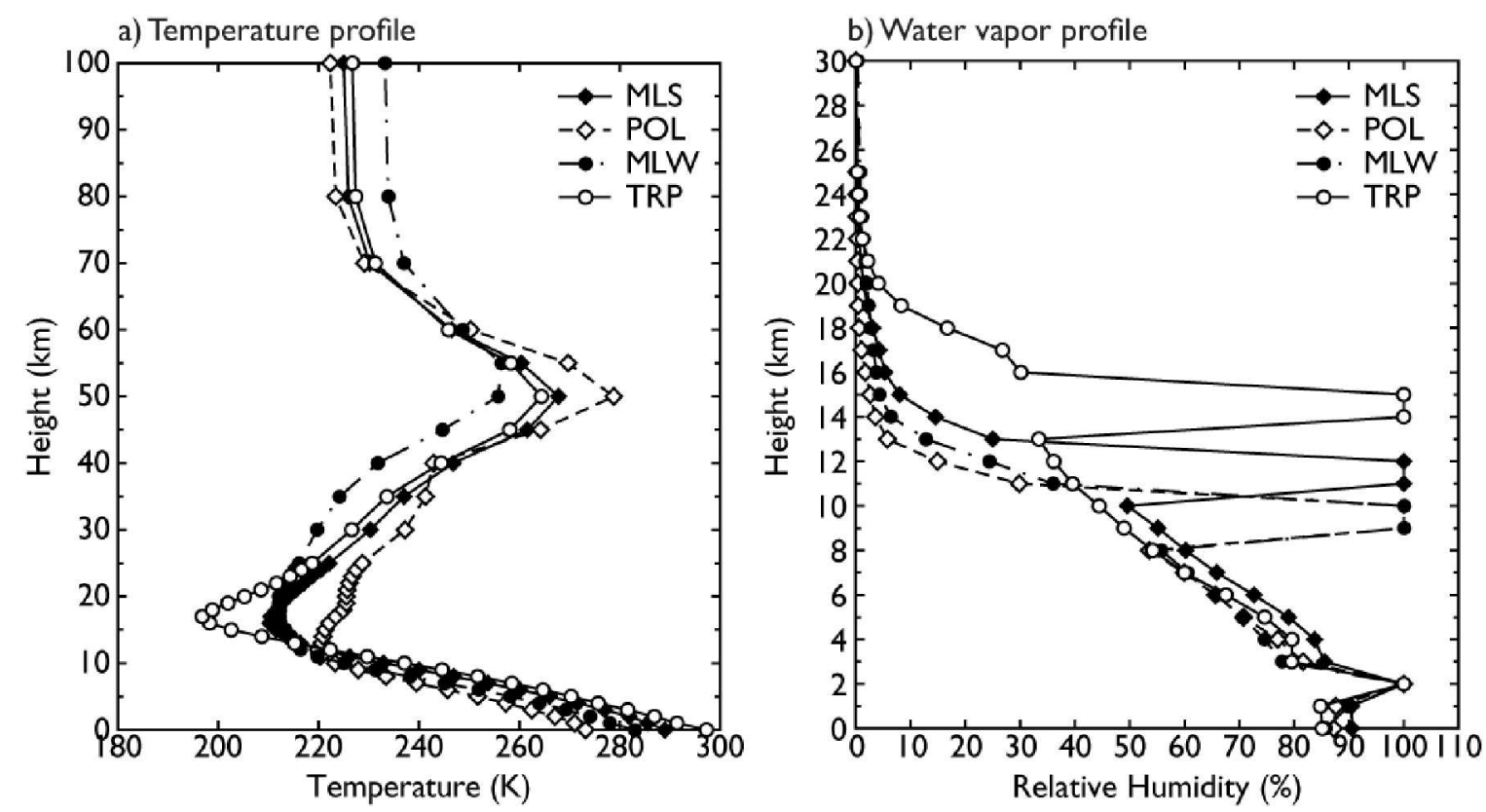

FIG. 4. Vertical profiles of (a) temperature and (b) moisture used as a basis for the forward models. The moisture profiles show saturation at levels that contain clouds. In this example the liquid water cloud is located at $2 \mathrm{~km}$ altitude and ice clouds are placed according to the tropopause location. 


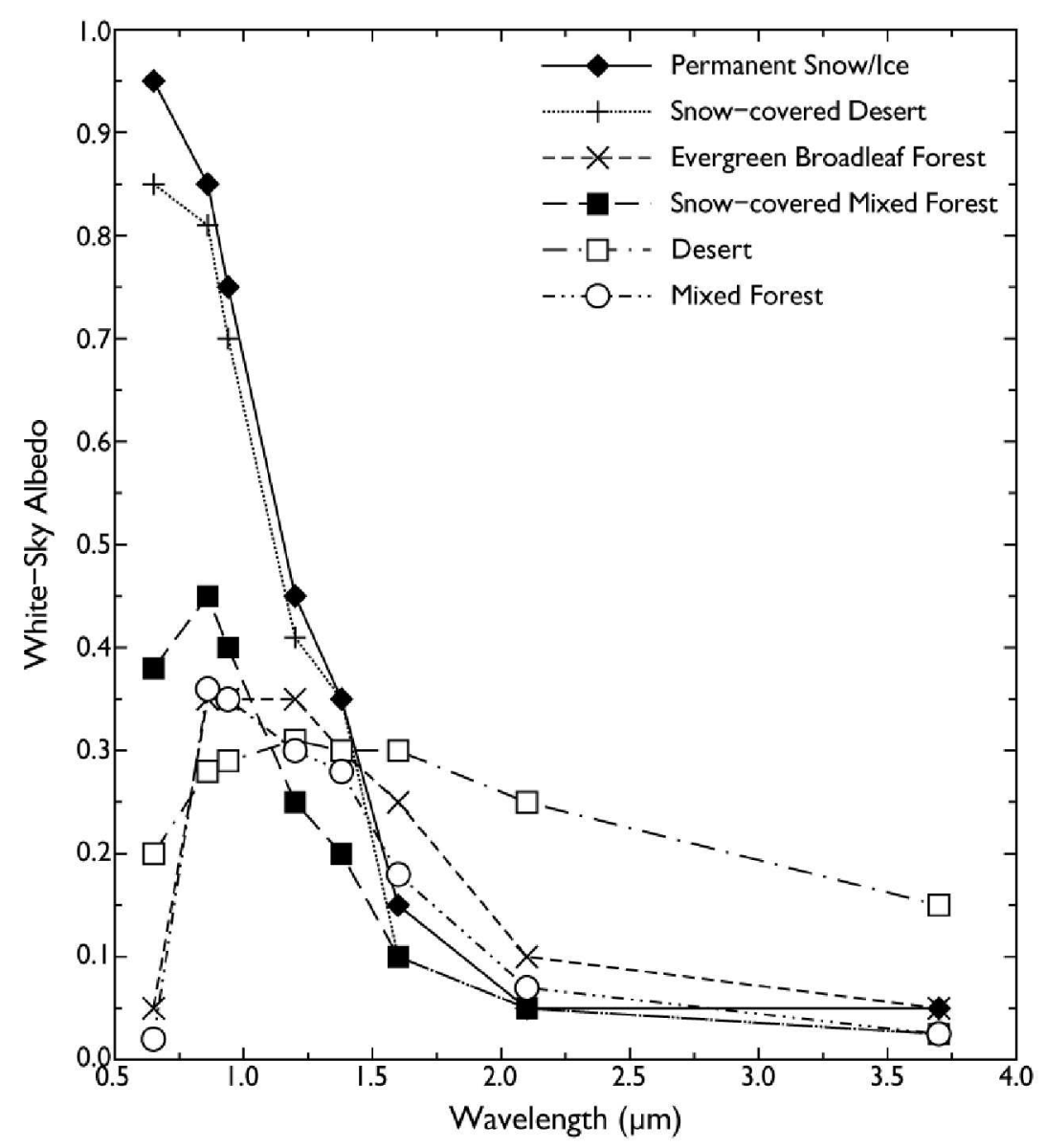

FIG. 5. White-sky albedo as a function of wavelength for selected IGBP ecosystem classifications used in the forward calculations. 
a) Dark ocean, liquid cloud at $2 \mathrm{~km}$

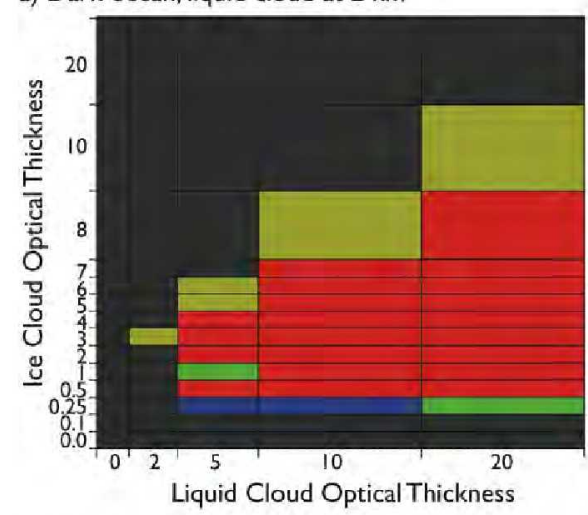

c) MLS profile, liquid cloud at $2 \mathrm{~km}$

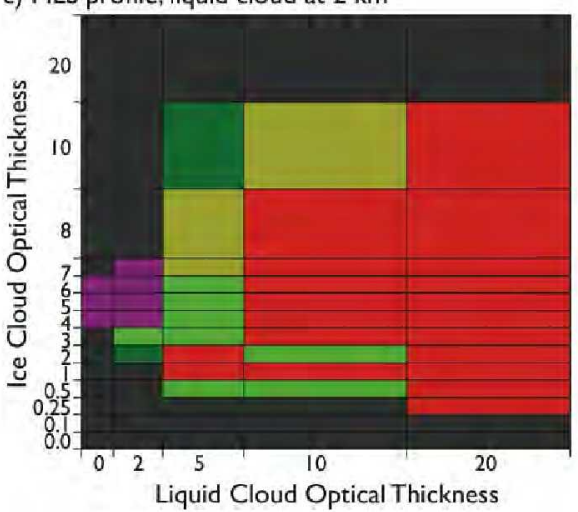

b) Dark ocean, liquid cloud at $4 \mathrm{~km}$
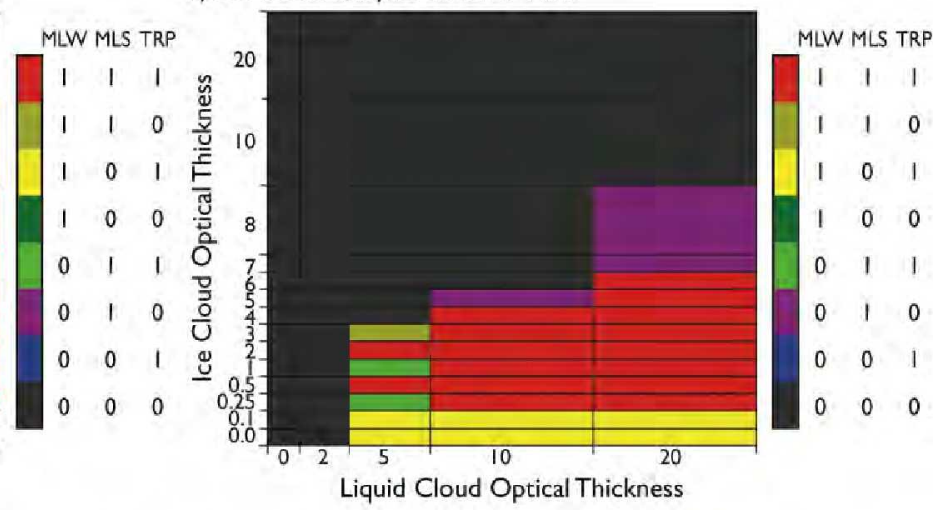

d) MLS profile, dark ocean, liquid cloud at $2 \mathrm{~km}$

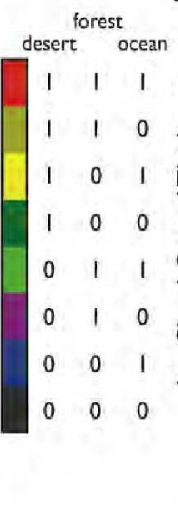

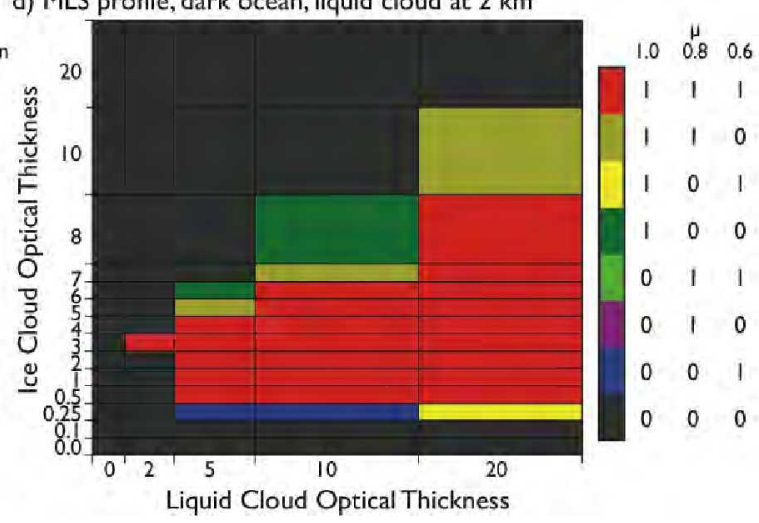

FIG. 6. MODIS multilayer cloud detection over various surfaces, water vapor content, and view zenith angle for a cross-section of DISORT simulations. Water vapor profiles are mid-latitude summer (MLS), mid-latitude winter (MLW) and mean tropical (TRP). Panel (a) indicates the detection of multilayer clouds over ocean when the lower layer liquid water cloud is placed at $2 \mathrm{~km}$ altitude and panel (b) for a lower layer liquid water cloud placed at $4 \mathrm{~km}$ altitude. The color bar identifies the selection of multilayer clouds for various atmospheric profiles containing different water vapor profiles. Panel (c) shows the MODIS multilayer cloud detection over various surfaces including desert, forest, and snow. Panel (d) shows multilayer cloud detection for various view zenith directions. 
MODIS Collection 5

a) Dark ocean, liquid cloud at $2 \mathrm{~km}$

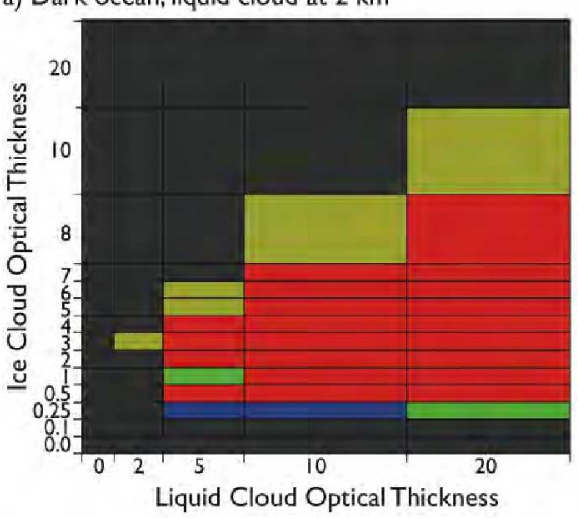

b) Dark ocean, liquid cloud at $4 \mathrm{~km}$

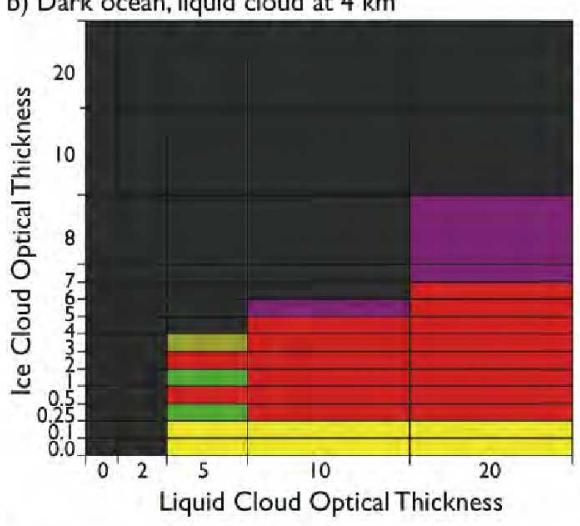

c) MLS profile, dark ocean, liquid cloud at $2 \mathrm{~km}$

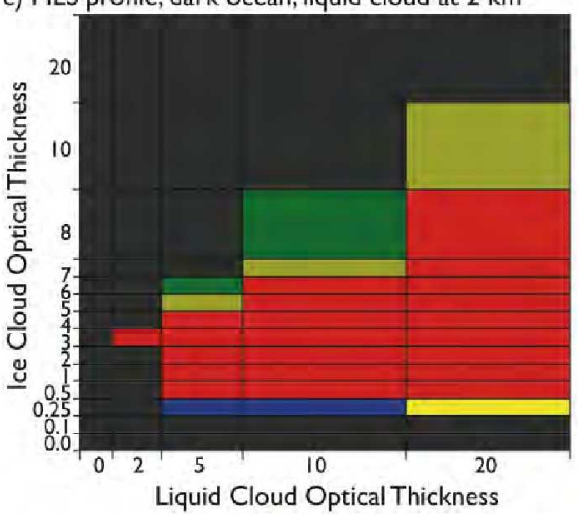

Pavolonis-Heidinger
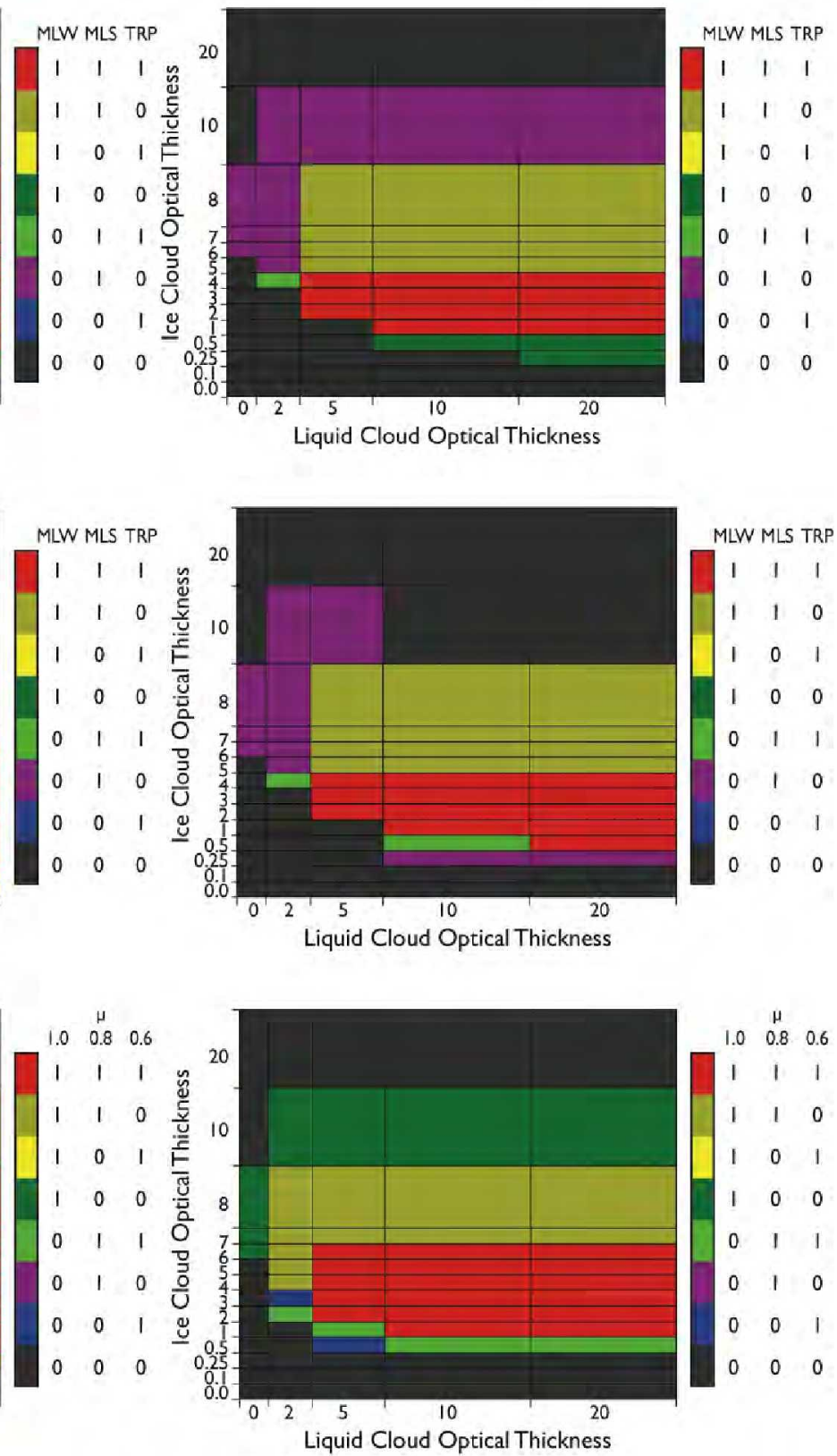

FIG. 7. Results of MODIS (left) and Pavolonis-Heidinger (right) multilayer cloud detection for a cross-section of DISORT simulations. Panel (a) indicates the detection of multilayer clouds over ocean when the lower layer liquid water cloud is placed at $2 \mathrm{~km}$ altitude and panel (b) for a lower layer liquid water cloud placed at $4 \mathrm{~km}$ altitude. The color bar identifies the selection of multilayer clouds for various atmospheric profiles containing different water vapor profiles. Panel (c) 
shows multilayer cloud detection for various view zenith directions.

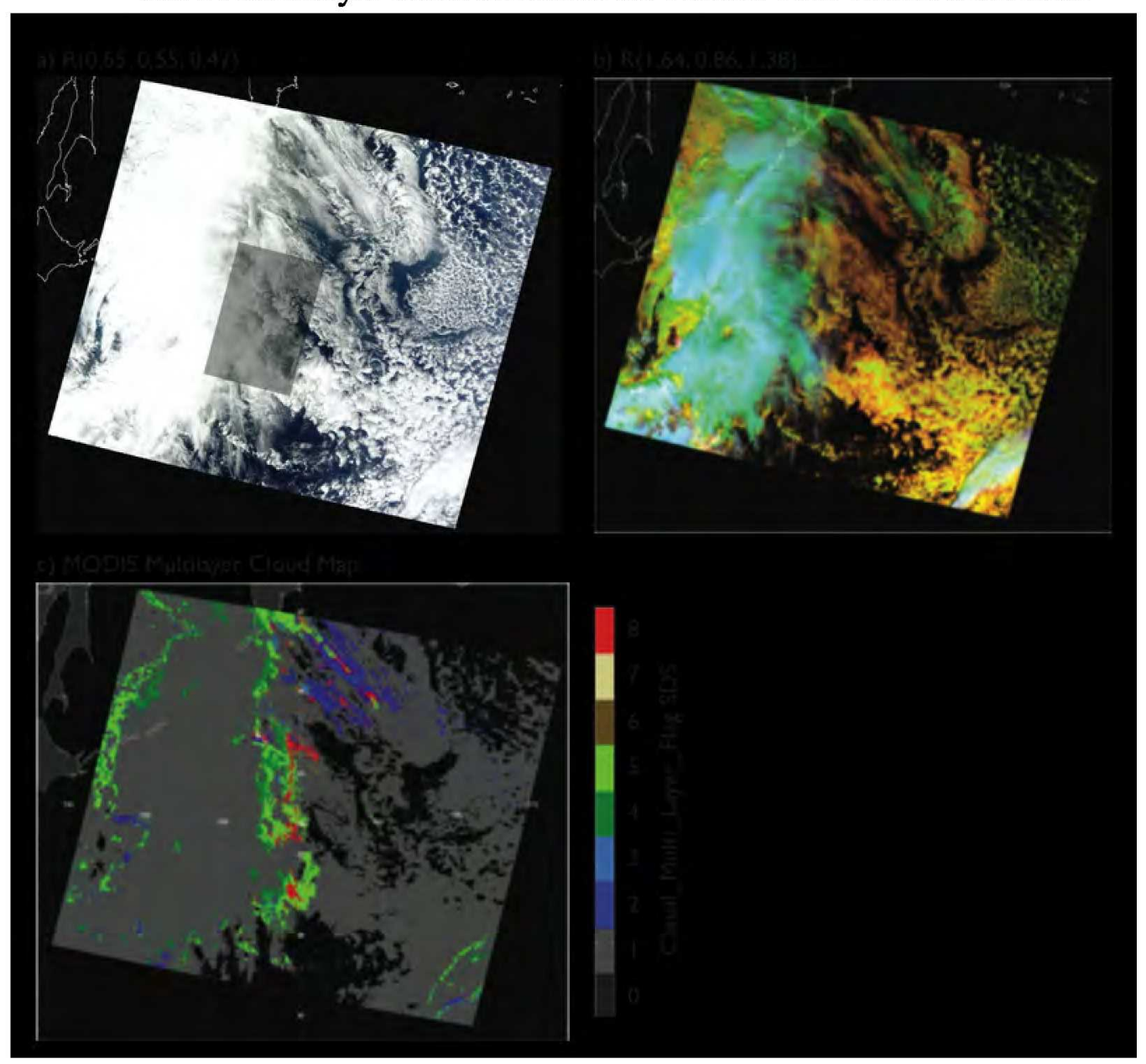

FIG. 8. Multilayer cloud over the western Pacific Ocean off Japan on 25 October 2008. Panel (a) is a true color composite of a Terra MODIS granule at 0015 UTC. Gray box indicates the area of interest presented in Figure 1. Panel (b) is a false color composite that more clearly shows the liquid water clouds (gold), ice clouds (blue) and multilayer clouds (green). Panel (c) is the multilayer cloud SDS that shows clear sky (0), single layer clouds (1), and multilayer clouds determined by various algorithm choices (2-8) (see Table 1). 
a) MODIS Multilayer Cloud Flag (All Phases)
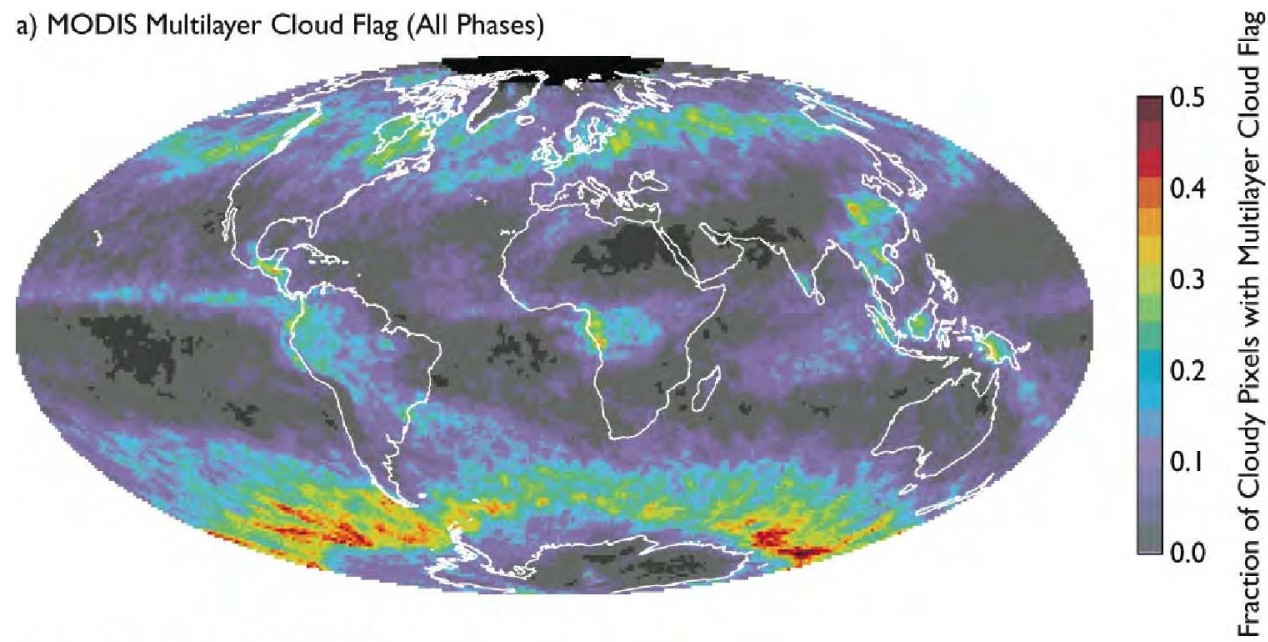

b) Combined Cloud Fraction

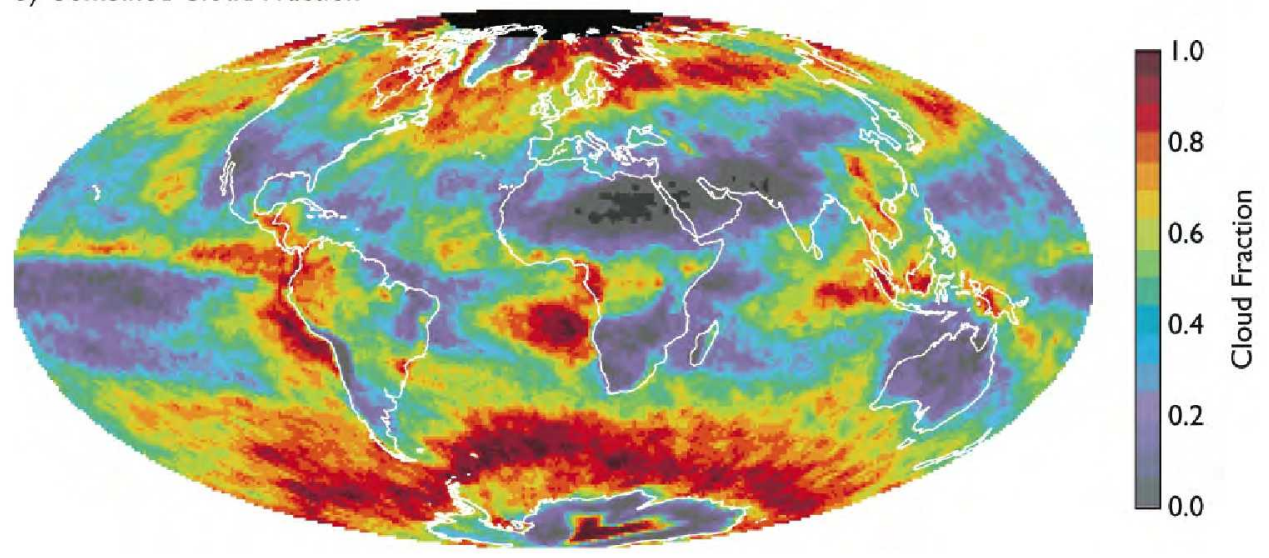

FIG. 9. Terra MODIS monthly level-3 global products for October 2008. Panel (a) shows the fraction of cloudy pixels with multilayer cloud flag identified (all phases), and panel (b) shows the combined cloud fraction. 


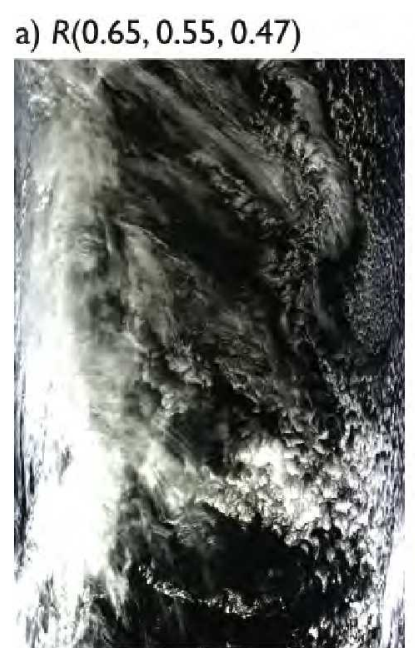

d) MODIS collection 5

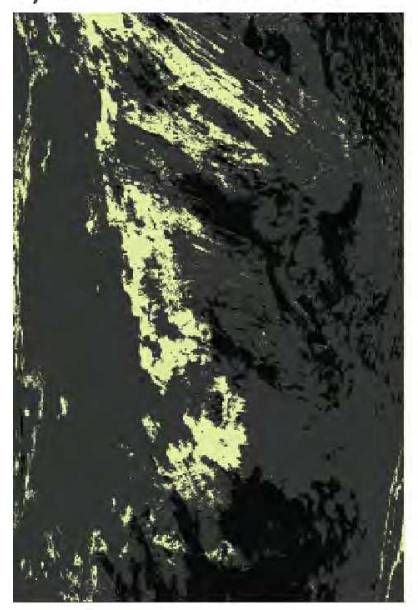

g) Cloud optical thickness
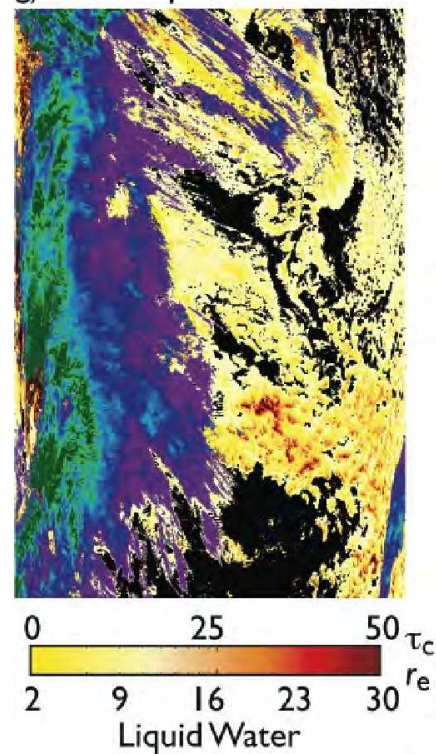

b) $R(1.64,0.86,1.38)$

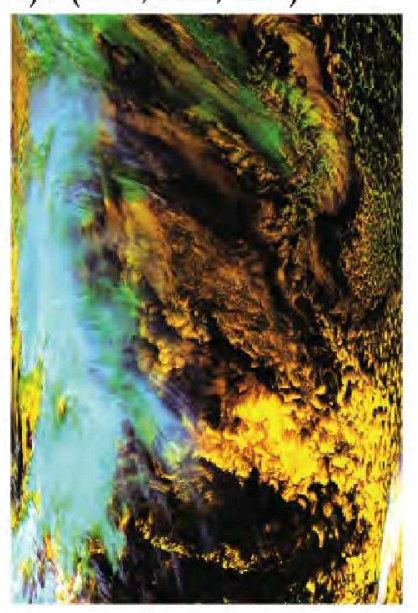

e) Pavolonis-Heidinger

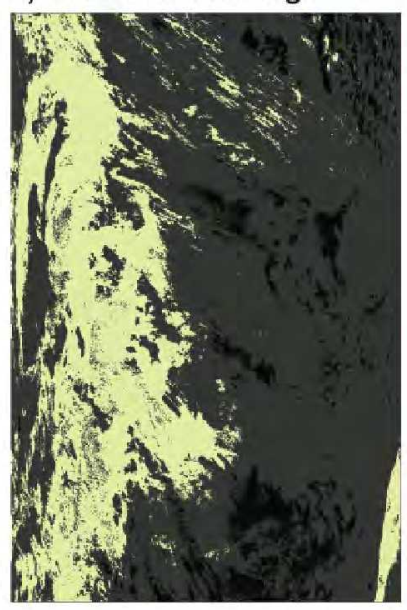

h) Cloud effective radius
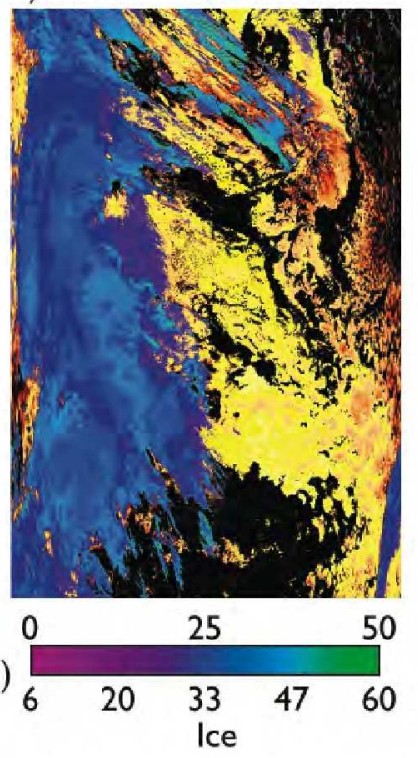

c) $R(0.55,1.64,2.13)$

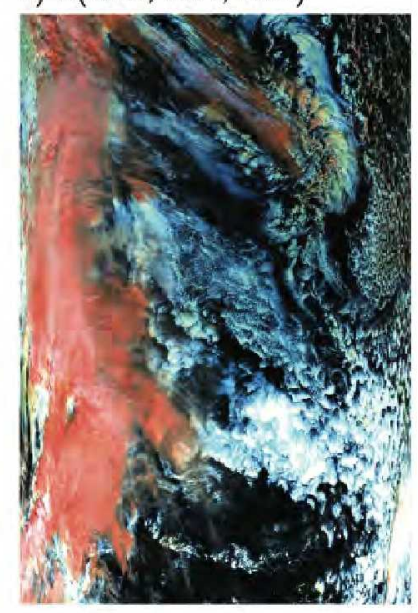

f) Nasiri-Baum

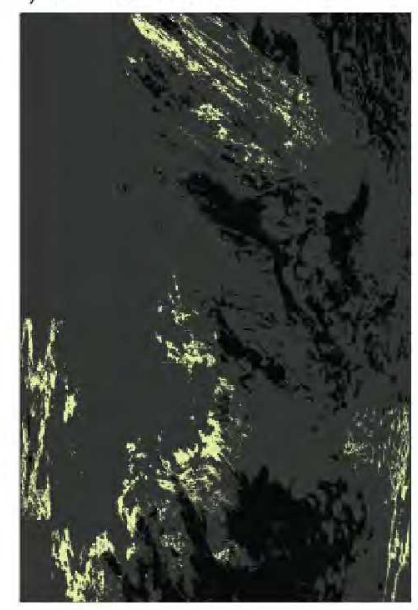


FIG. 10. Multilayer cloud analysis and cloud optical properties over the western Pacific Ocean off Japan as acquired by Terra MODIS on 25 October 2008 at 0015 UTC. Panel (a) is a true color composite of one MODIS granule and panel (b) is a false color composite, showing liquid water clouds in gold, ice clouds in blue and white, and overlapped clouds in green. Panel (c) is another false color composite showing ice clouds in pink and liquid clouds in blue. Panels (d), (e), and (f) show multilayer cloud identification using the MODIS collection 5, Pavolonis-Heidinger, and Nasiri-Baum algorithms, respectively. Panels (g) and (h) show retrieved values of cloud optical thickness and effective radius for liquid water and ice clouds. 